\title{
Palmeiras (Arecaceae) em Santa Catarina, sul do Brasil
}

\author{
Guilherme Alves Elias', Kelen Pureza Soares², Roseli Lopes da Costa Bortoluzzi ${ }^{3}$ \\ \& Robson dos Santos ${ }^{1}$
}

\author{
'Universidade do Extremo Sul Catarinense, Herbário Pe. Dr. Raulino Reitz (CRI), Av. Universitária, 1 105, CEP 88.806-000, Criciúma, SC, Brasil. \\ guilherme@unesc.net \\ ¿Universidade Federal de Santa Maria, Herbário do Departamento de Ciências Florestais, Camobi, Prédio 44, \\ CEP 97.105-900, Santa Maria, RS, Brasil. \\ 3Universidade do Estado de Santa Catarina, Herbário Lages da Universidade do Estado de Santa Catarina, \\ Av. Luís de Camões, 2090, CEP 88.520-000, Lages, SC, Brasil.
}

Recebido em 3.III.2016

Aceito em 05.II.2018

DOI $10.21826 / 2446-8231201873202$

RESUMO - Este estudo teve como objetivo realizar o levantamento e atualização das informações sobre as Palmeiras (Arecaceae) com ocorrência natural em Santa Catarina, Brasil. Foram confirmadas 11 espécies nativas: Astrocaryum aculeatissimum (Schott) Burret, Attalea dubia (Mart.) Burret, Bactris setosa Mart., Butia catarinensis Noblick \& Lorenzi, B. eriospatha (Mart. ex Drude) Becc., Euterpe edulis Mart., Geonoma elegans Mart., G. gamiova Barb.Rodr., G. schottiana Mart., Syagrus romanzoffiana (Cham.) Glassman, Trithrinax acanthocoma Drude e, excluída G. pohliana Mart. por não ter sido confirmada ocorrência natural no estado de Santa Catarina.

Palavras-chave: biodiversidade, Floresta Atlântica, florística, Palmae, taxonomia

ABSTRACT - Palms (Arecaceae) from Santa Catarina, Southern Brazil. This study aimed to survey and update information on native Palms (Arecaceae) occurring in the Brazilian state of Santa Catarina. We encountered 11 native species: Astrocaryum aculeatissimum (Schott) Burret, Attalea dubia (Mart.) Burret, Bactris setosa Mart., Butia catarinensis Noblick \& Lorenzi, B. eriospatha (Mart. ex Drude) Becc, Euterpe edulis Mart., Geonoma elegans Mart., G. gamiova Barb.Rodr., G. schottiana Mart., Syagrus romanzoffiana (Cham.) Glassman, Trithrinax acanthocoma Drude but excluded G. pohliana Mart. since its natural occurrence in the state of Santa Catarina remains unconfirmed.

Keywords: Atlantic Rainforest, biodiversity, floristics, Palmae, taxonomy

\section{INTRODUÇÃO}

As palmeiras (Arecaceae) estão entre as mais longevas e representativas plantas vasculares do globo e, nas regiões tropicais e subtropicais apresentam elevada diversidade, e grande importância ecológica e econômica (Balick \& Beck 1990, Galetti \& Aleixo 1998, Maunder et al. 2001). A família é constituída por 252 gêneros e aproximadamente 2.600 espécies (Dransfield et al. 2008). No Brasil são 37 gêneros e 285 espécies, sendo 125 endêmicas (Leitman et al. 2015). No estado de Santa Catarina foram confirmadas por Reitz (1974) a presença de 11 espécies nativas em oito gêneros. Estas informações foram publicadas juntamente com a Flora Ilustrada Catarinense em um fascículo dedicado às palmeiras, onde foi dado tratamento para os gêneros nativos, além de outros 19 gêneros cultivados e/ou exóticos (Reitz 1974). No entanto, Leitman et al. (2015) apontam a ocorrência de 12 espécies nativas para Santa Catarina, incluindo Geonoma pohliana Mart., anteriormente citada apenas para os estados da Bahia, Espírito Santo, Rio de Janeiro e São Paulo (Lorenzi et al. 2010).
Os representantes nativos em Santa Catarina estão distribuídos em todas as formações vegetacionais: Floresta Ombrófila Densa, Floresta Ombrófila Mista (Floresta Nebular, Floresta de Faxinais e Campos Naturais), Floresta Estacional Decidual e Restinga, conforme a classificação do IBGE (2012). Contudo, é na Floresta Ombrófila Densa em que as variáveis ambientais são mais favoráveis para o surgimento de um grande contingente de diversidade $\mathrm{e}$ densidade de espécies de palmeiras (Reitz 1974).

Assim posto, o presente trabalho visa apresentar um levantamento atualizado e completo das palmeiras de Santa Catarina, chave dicotômica para espécies, descrições, tratamento taxonômico, ilustrações, comentários sobre os aspectos ecológicos e ocorrência natural das espécies nativas no estado catarinense.

\section{MATERIAL E MÉTODOS}

O levantamento, a identificação e a descrição das palmeiras de Santa Catarina tiveram como base materiais coletados em expedições botânicas realizadas entre os anos 2014 e 2016 que contemplaram todas as regiões 
fitogeográficas do estado (IBGE 2012), cujos espécimes foram depositados no Herbário Pe. Dr. Raulino Reitz (CRI) da Universidade do Extremo Sul Catarinense (UNESC) e, a partir de coleções depositadas nos herbários catarinenses CRI, FLOR, HBR, FURB, JOI e LUSC, além de material adicional do herbário HDCF (Universidade Federal de Santa Maria).

Para a identificação botânica foram consultadas chaves para gêneros e espécies em bases bibliográficas como Reitz (1974), Dransfield et al. (2008), Lorenzi et al. (2010), Soares et al. (2014) e, para a citação de autores de gêneros e espécies, a base eletrônica (IPNI 2016).

Para as mensurações e descrições das estruturas vegetativas seguiram-se os conceitos adotados por Tomlinson (1990), onde o termo "pina" foi usado para cada segmento das folhas pinadas e, "segmento", para as folhas palmado-flabeliformes. As medidas referentes à largura da bráctea peduncular e da bainha das folhas foram tomadas na sua porção mais larga e o diâmetro do estipe, entre 10-20 cm acima do solo. As medidas de estruturas reprodutivas como flores, frutos e endocarpos foram tomadas com auxílio de paquímetro digital e das partes vegetativas, com auxílio de trena.

A chave de identificação foi elaborada em nível específico com caracteres que possibilitam a identificação dos espécimes em campo e em material herborizado completo. Porém, cada gênero foi tratado com destaque quanto a sua distribuição global, caracteres morfológicos úteis para identificação e composição florística no Brasil e em Santa Catarina.

Os mapas com a distribuição natural das espécies nos municípios de ocorrência, foram confeccionados a partir de dados oriundos das etiquetas de exemplares de herbário examinados, em observações de ocorrência in situ registradas durante as expedições botânicas em campo, em informações de trabalhos publicados (com atualização dos nomes das espécies, quando necessário), com os dados do Inventário Florístico Florestal de Santa Catarina (Vibrans et al. 2010) e, nas informações detalhadas por Reitz (1974).

A maioria das ilustrações das espécies está sendo utilizada conforme Soares et al. (2014), com prévia autorização da Revista Rodriguésia, as demais são inéditas e foram incluídas neste trabalho.

\section{RESULTADOS E DISCUSSÃO}

Arecaceae Schultz Sch., Nat. Syst. Pflanzenr. 317. 1832. Palmae Jussieu, Gen. Pl.: 37. 1789.

Tipo: Areca L. (A. catechu L., Sp. Pl. 2: 1189. 1753.).

\section{Chave de identificação das espécies nativas de palmeiras (Arecaceae) em Santa Catarina.}

1. Palmeira com folhas palmado-flabeliformes (Fig. 14G); inflorescência (Fig. 14H) composta por um profilo e 6-9 brácteas pedunculares...........8.1 Trithrinax acanthocoma 1'. Palmeira com folhas pinadas; inflorescência composta por um profilo e uma única bráctea peduncular.

2. Raque foliar, pinas, bainha e bráctea peduncular armadas. 3. Pinas das folhas arranjadas regularmente e inseridas em um único plano sobre a raque (Fig. 1A), albas na parte abaxial, 59-85 de cada lado; bráctea peduncular $60-85 \mathrm{~cm}$ compr.; frutos piriformes (Fig. 1C), epicarpo revestido por indumento fino e rígido de cor castanha ...

\subsection{Astrocaryum aculeatissimum}

3'. Pinas das folhas arranjadas irregularmente e inseridas em mais de um plano sobre a raque (Fig. $1 \mathrm{~J}$ ), verdes na parte abaxial, com 17-62 de cada lado da raque; bráctea peduncular 18-57 cm compr.; frutos globosos (Fig. 1I), epicarpo glabro e preto 3.1 Bactris setosa

2'. Raque foliar, pinas, bainha e bráctea peduncular inermes.

4. Bráctea peduncular papirácea.

5. Bainha das folhas 1-2,1 m compr.; flores não imersas em alvéolos nas ráquilas 5.1 Euterpe edulis 5'. Bainha das folhas com variação de $12-35 \mathrm{~cm}$ compr.; flores imersas em alvéolos nas ráquilas.

6. Inflorescência espiciforme (Fig. 9B)

6.1 Geonoma elegans

6'. Inflorescência paniculada.

7. Raque foliar de indivíduos adultos 9-48 pinas de cada lado; pinas com distribuição regular ao longo da raque (Fig. 9I), com até 3,2 cm larg. (exceto indivíduos jovens, que podem apresentar pinas mais largas)

6.3 Geonoma schottiana

7'. Raque foliar de indivíduos adultos com até 17 pinas de cada lado; pinas com distribuição irregular, intercalada com pinas de larguras variadas (Fig. 9D), 1-14 cm larg

4'. Bráctea peduncular lenhosa.

6.2 Geonoma gamiova

8. Pinas inseridas em diferentes planos (ângulos) sobre a raque, conferindo à folha um aspecto plumoso; bráctea peduncular fissurada longitudinalmente na parte externa. 9. Raque das folhas 6-9 $\mathrm{m}$ compr.; flores pistiladas $2,5-4,0$ cm compr.; frutos (Fig. 1G) 6,0-8,5 × 3-4 cm

2.1 Attalea dubia

9'. Raque das folhas 1,4-5,3 m compr.; flores pistiladas 5-8 mm compr.; frutos (Fig. 14D) 1,9-4,2 × 1,3-2,9 cm.

7.1 Syagrus romanzoffiana 8' Pinas inseridas num mesmo plano ou em planos muito pouco diferenciados, formando um "V" sobre a raque sem, no entanto, conferir um aspecto plumoso à folha; bráctea peduncular não fissurada externamente.

10. Bráctea peduncular lanuginosa externamente; endocarpos globosos (Fig. 5H) 1,3-1,7 cm larg.

4.2 Butia eriospatha

10 '. Bráctea peduncular glabra ou levemente coberta por tomento externamente; endocarpos estreito-ovoides (Fig. 5D) $0,6-1,3 \mathrm{~cm}$ larg 4.1 Butia catarinensis 
Gêneros e espécies de Arecaceae nativas de Santa Catarina

1 Astrocaryum G. Mey., Prim. Fl. Esseq. 265-266.

1818.

Tipo: Astrocaryum aculeatum G.Mey, Prim. Fl. Esseq. 266. 1818.

O gênero está incluído na subfamília das Arecoideae, tribo Cocoeae, subtribo Bactridinae, sendo comumente encontrado em ecossistemas tropicais da América do Sul e nas florestas da América Central (Kahn 2008). Abrange várias formas de vida, desde grandes palmeiras que alcançam o dossel da floresta, até pequenas acaulescentes no estrato arbustivo (Kahn 2008). Segundo o mesmo autor, em revisão do gênero, 26 espécies ocorrem no Brasil, sendo oito endêmicas. No entanto, a Lista de Espécies da Flora do Brasil apresenta 22 espécies sendo cinco endêmicas (Leitman et al. 2015). Em Santa Catarina, somente Astrocaryum aculeatissimum (Schott) Burret avança até o norte do estado (Reitz 1974).

1.1 Astrocaryum aculeatissimum (Schott) Burret, Repert. Spec. Nov. Regni Veg. 35: 152. 1934. Tipo: Brasil, Rio de Janeiro: s. d., Schott 4113 (“Tipo:" M; F negs. 21150, 31310).

(Figs. 1A-E, 2)

Estipe cespitoso, 4-10 m alt., $60-17 \mathrm{~cm}$ diâm., revestidos de acúleos pretos com até $8 \mathrm{~cm}$ compr. Folhas pinadas, 10-20 contemporâneas; bainha e pecíolo com 1,8-3,7 m compr.; raque 1,4-6,4 m compr., contendo 59-85 pinas de cada lado, regularmente arranjadas e inseridas em um mesmo plano sobre a raque, pinas estreito-lanceoladas, 23-38 cm compr., verde-escuras na parte adaxial e albas na parte abaxial. Inflorescências interfoliares, paniculadas e pêndulas, $60 \mathrm{~cm}$ compr.; flores amarelo-creme; profilo, $27-38 \times 3-7 \mathrm{~cm}$, bráctea peduncular revestida de espinhos e pelos rígidos, $60-85 \mathrm{~cm}$ compr. total, $23-40 \times 12-17 \mathrm{~cm}$ de parte expandida; pedúnculo revestido por espinhos, 48-57 cm compr.; raque $37-48 \mathrm{~cm}$ compr., flores estaminadas, $0,5-1,1 \times 0,02-0,07 \mathrm{~cm}$ e apenas uma flor pistilada na base, $0,4-1,0 \times 0,04-0,07 \mathrm{~cm}$. Frutos piriformes, 5-6 × 3-4 $\mathrm{cm}$, revestidos por indumento fino e rígido, decíduo, de cor castanha; mesocarpo carnoso e adocicado; endocarpo rígido, endosperma homogêneo com cavidade interna. Eófilo bífido.

Nomes populares: ariri, ariri-açu, coco-airi, brejaúba, brejaúva, iri, tucum-verdadeiro.

Material examinado: BRASIL, SANTA CATARINA, Garuva, Morro da Brejaúba, 1.XII.1952, R. Reitz 5681 (HBR), 4.II.1952, R. Reitz 4217 (HBR), 3.X.1957, R. Reitz \& R.M. Klein 5026 (HBR).

Espécie seletiva heliófita e higrófita ocorrente na costa Atlântica nos estados da Bahia, Espirito Santo, Minas Gerais, Rio de Janeiro, São Paulo, Paraná e Santa Catarina, geralmente em florestas úmidas de baixa altitude, em solos não inundáveis, em capoeiras e pastagens (Lorenzi et al. 2010). Em Santa Catarina apresenta distribuição descontínua e restrita, estando limitada ao extremo nordeste do Estado, precisamente no município de Garuva, onde forma pequenos agrupamentos, observados no Morro da Brejaúba a $50 \mathrm{~m}$ de altitude (Reitz 1974).

Apesar de muito rara no Estado, a espécie apresenta ampla distribuição no decorrer da costa brasileira (Região Sudeste), e está presente em diversas unidades de conservação. Enquadra-se na categoria LC (menos preocupante), segundo a Lista Vermelha de Espécies da Flora do Brasil, onde estão agrupadas as espécies mais abundantes e amplamente distribuídas (CNCFlora 2012), ocorrendo em alta densidade, acima de 500 indivíduos/ ha $^{-1}$ (Pires 2006).

Por apresentar coloração escura e alta durabilidade, seu estipe é tradicionalmente utilizado na marchetaria e para confecção de bengalas. As suas folhas podem ser utilizadas na fabricação de armações estruturais de casebres e muitas vezes como vassouras rústicas (Reitz 1974). O endosperma apresenta ação vermífuga (Lorenzi et al. 2010).

2 Attalea Kunth, Nov. Gen. Sp. [H.B.K.] 309. 1815. Tipo: A. amygdalina Kunth. Nov. Gen. Sp. 1: 310. 1816.

O gênero está incluído na subfamília Cocosoideae, tribo Attaleae, diferindo dos demais membros da tribo por ter dois tipos de inflorescências, geralmente na mesma planta: um com flores somente estaminadas e outro com flores andróginas (Reitz 1974, Glassman 1999, Dransfield et al. 2008, Lorenzi et al. 2010).

As espécies deste gênero apresentam caule subterrâneo, por vezes muito curto, ou caulescente. Ocorre em quase todos os estados da federação, excluindo Rio Grande do Norte e Rio Grande do Sul, tendo espécies que também ocorrem fora dos limites brasileiros, sendo estas na América Central, Colômbia, Guianas, Haiti, México, Paraguai, Peru, Suriname e Venezuela (Henderson et al. 1995, Dransfield et al. 2008, Leitman et al. 2015). Segundo a Lista das Espécies da Flora do Brasil, o gênero é representado por 30 espécies, sendo 16 endêmicas (Leitman et al. 2015).

2.1 Attalea dubia (Mart.) Burret, Notizbl. Bot. Gart. Berlin-Dahlem 10: 516, 537. 1929. Tipo: Brasil, Rio de Janeiro: prov. Sebastianopolitana (lectótipo, Martius, Hist. Natur. Palm. 3: t. 169, fig. 6. 1845, designado por Glassman, 1977).

$$
\text { (Figs. 1F, G, 3) }
$$

Estipe solitário, $5-25 \mathrm{~m}$ alt., 30-50 cm diâm., apresentando superfície lisa. Folhas pinadas, $20 \times 30$ contemporâneas; bainha 1,2-1,8 m compr.; pecíolo 10$16 \mathrm{~cm}$ compr.; raque 6-9 m compr., contendo 100-114 pinas de cada lado, inseridas em 3-4 planos e dispostas irregularmente sobre a raque, pinas medianas, $42-67 \mathrm{~cm}$ compr.. Inflorescências interfoliares com flores amareladas, pistildas e estaminadas ou somente com flores estaminadas 


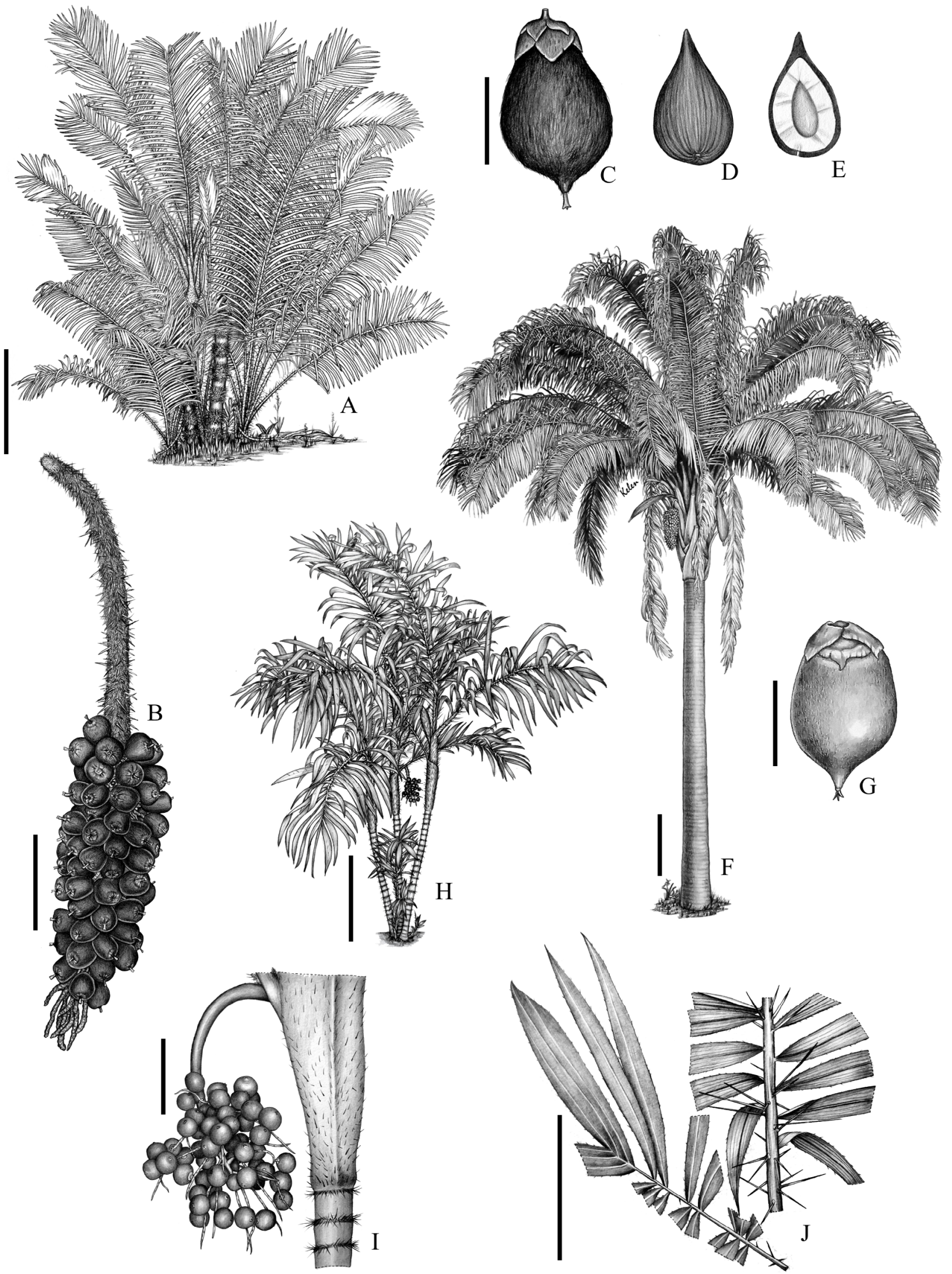

Figs. 1A-J. A-E. Astrocaryum aculeatissimum (R. Reitz \& R. M. Klein 5026). A. Hábito; B. Infrutescência; C. Fruto; D. Endocarpo, vista exterior; E. Endocarpo, vista interior F, G. Attalea dubia (G. A. Elias et al. 1). F. hábito; G. fruto. H-J. Bactris setosa (K. Soares \& L. Witeck). H. Hábito; I. Detalhe da infrutescência; J. Detalhe da folha. Barras: Figs. A, F, H $=1 \mathrm{~m} ;$ Figs. B, I, J $=10 \mathrm{~cm}$; Figs. C, D, E, G $=3 \mathrm{~cm}$. 


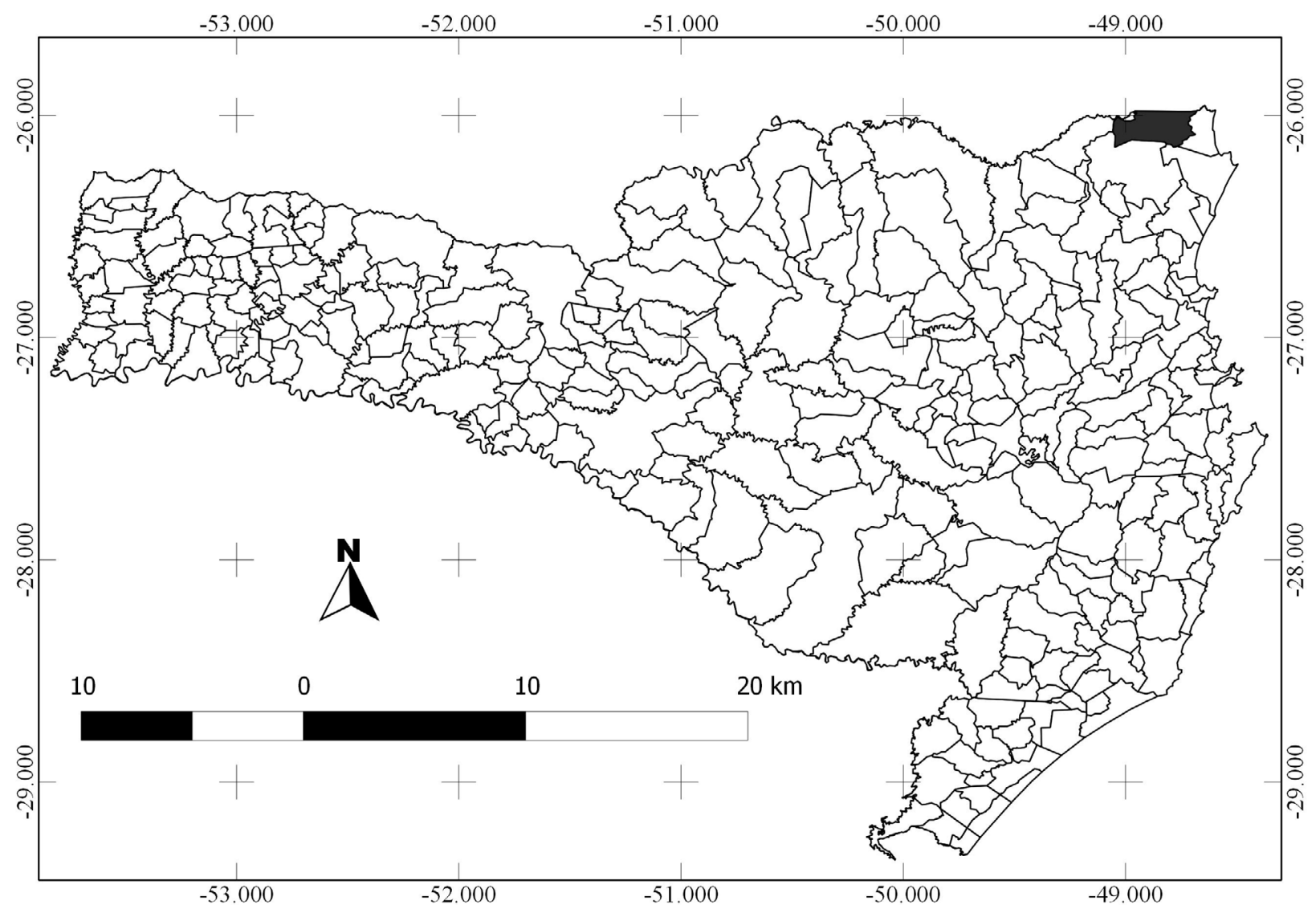

Fig. 2. Mapa de distribuição da espécie Astrocaryum aculeatissimum (Schott) Burret em Santa Catarina.

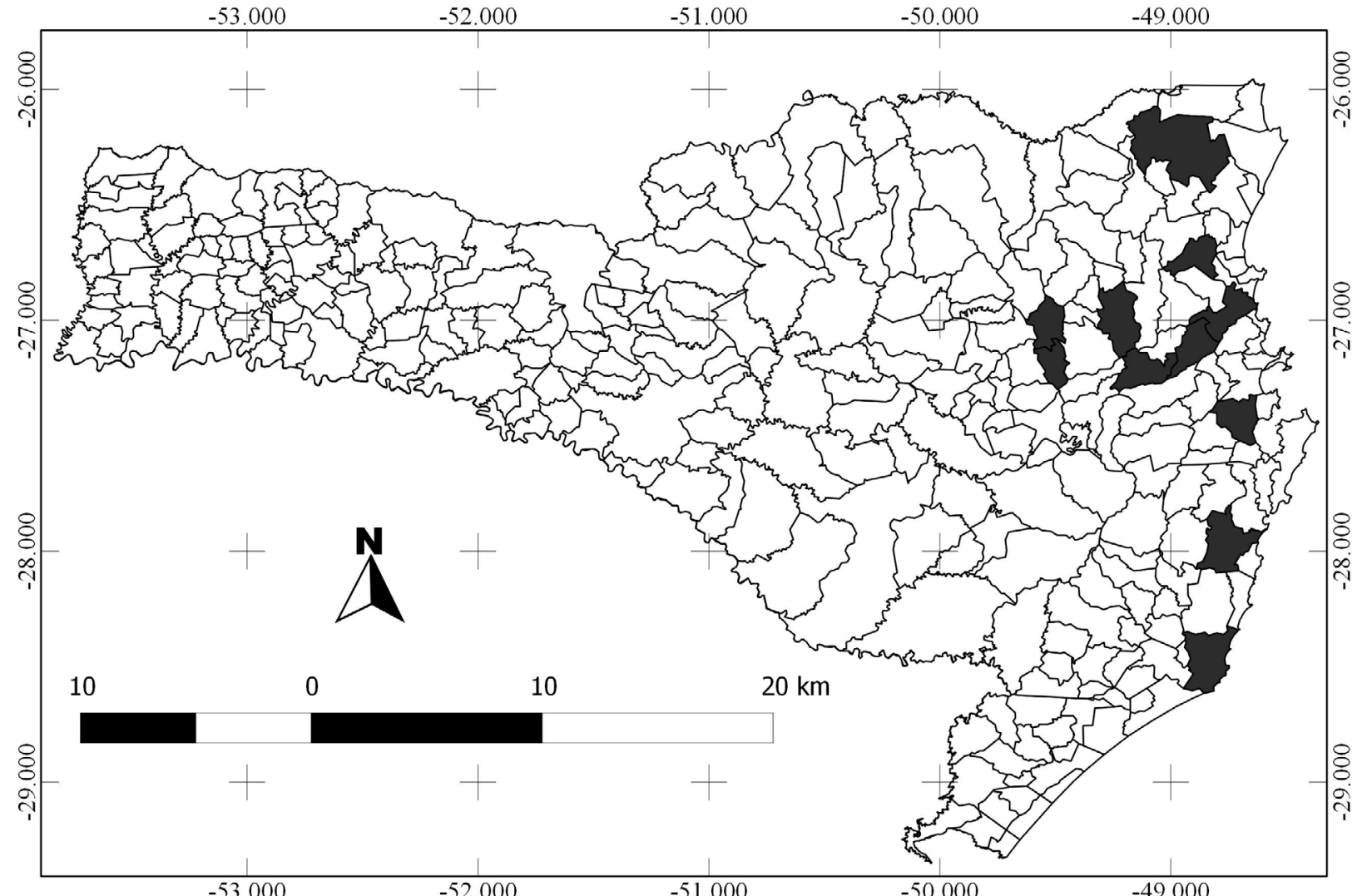

Fig. 3. Mapa de distribuição da espécie Attalea dubia (Mart.) Burret em Santa Catarina. 
na mesma planta; profilo oculto com 7-12 cm compr., bráctea peduncular $83-140 \mathrm{~cm}$ compr. total, $23-42 \mathrm{~cm}$ de parte expandida; pedúnculo $1 \mathrm{~m}$ compr.; raque 6-7 m compr., contendo 9-18 ráquilas; ráquilas das inflorescências andróginas 10-15 cm compr.; ráquilas da inflorescência masculina $18 \mathrm{~cm}$ compr., flores estaminadas distribuídas em fileira dupla em um dos lados dos ramos; flores estaminadas $2 \mathrm{~cm}$ compr.; flores pistiladas 2,5-4,0 × 1,5-1,7 cm, 6-10 estames. Frutos 6,0-8,5 $\times 3-4 \mathrm{~cm}$, perianto persistente; mesocarpo amarelo, suculento-fibroso e adocicado; endocarpo ósseo 2,7-3,8 $\times 0,8-1,7 \mathrm{~cm}$, elíptico, contendo 1-2(-3) sementes; endosperma homogêneo. Eófilo simples.

Nomes populares: camarinha, coqueiro-indaiá, indaiá, indaiá-açu, inaiá, naiá, palmito-do-chão.

Material examinado: BRASIL, SANTA CATARINA, Blumenau, 19.IX.2009, A. Stival-Santos, E. Legal \& S. Silveira 3301 (FURB); Brusque, Azambuja, 02.VIII.1947, R. Reitz 1810 (HBR); Itajaí, 1956, R. Reitz $s / n^{\circ}$ (HBR 36597); Itapoá, Reserva Volta Velha, G. A. Elias et al. 1 (CRI); Salto do Pilão, 19.X.1958, R. Reitz \& R. M. Klein 7361 (HBR); Luís Alves, Braço Joaquim, 04.X.1954, $R$. Reitz \& R. M. Klein 2242 (HBR).

Espécie heliófita e seletiva higrófita, distribuída desde o Espírito Santo até Santa Catarina, onde apresenta distribuição irregular e descontínua, variando entre 20 e $250 \mathrm{~m}$ de altitude, sendo mais frequente ao nordeste do Estado, principalmente nos municípios de Garuva, Itapoá e Joinville. Nos terrenos rochosos forma agrupamentos, principalmente nos municípios de Ibirama e de Lontras, também pode ser observada em campos, situados em topos de morro, sendo comum nos arredores do município de Luís Alves (Reitz 1974).

Sua distribuição, ainda que irregular, apresenta-se em densas populações, sendo uma característica da espécie persistir e desenvolver-se em áreas perturbadas (Henderson et al. 1995, Henderson 2002). Durante as expedições foi localizado um indivíduo mais ao sul, no município de Laguna, não relatado anteriormente na literatura, este estava afastado do meio urbano e da proximidade de residências.

Seu estipe e folhas são utilizados na fabricação e cobertura de casas rústicas (Lorenzi et al. 2010), embora tenha potencial paisagístico, é de difícil transplante. Deu o nome a cidade catarinense de Indaial (Reitz 1974).

3 Bactris Jacq. ex Scop., Intro. Hist. nat. 70. 1777. Lectótipo: B. minor Jacq., nom illeg. B. guineensis (L) H. E. Moore, Gentes Herb. 9: 251. 1963.

O gênero está incluído na subfamília das Cocosoideae, tribo Bactrideae, subtribo Bactridinae (Dransfield et al. 2008). É um dos grupos de palmeiras mais diversos na região Neotrópica, e o maior gênero de palmeiras do Brasil, tendo sua maior diversidade na região Amazônica, com 36 espécies. A ocorrência também abrange outros biomas, excluindo a Caatinga e os Campos Sulinos (Cascante 2000, Lorenzi et al. 2010).

A maioria das espécies apresenta de pequeno a médio porte, geralmente cespitosas (Lorenzi et al. 2010).

Para as Américas, Henderson et al. (1995) reconheceram 64 espécies. Na Lista da Flora do Brasil foram reconhecidas 45 espécies, sendo 13 endêmicas e 15 variedades, sendo uma endêmica (Leitman et al. 2015). Em Santa Catarina ocorre apenas uma espécie.

3.1 Bactris setosa Mart., Hist. Nat. Palm. 2: 94. 1926. Tipo: BRASIL. RIO DE JANEIRO: s. loc., s.d., $C$. Martius s.n. (holótipo, M; F neg. 18628, n.v.).

(Figs. 1H-J, 4)

Estipes múltiplos, espinescentes, 0,8-6 m alt., $3-6 \mathrm{~cm}$ diâm., espinhos 2-8 cm compr., dispostos em torno dos entrenós. Folhas pinadas, 4-10 por estipe, bainha, pecíolo, raque e pinas moderadamente armados; espinhos com até $6 \mathrm{~cm}$ compr., achatados; bainha $18-33 \mathrm{~cm}$ compr.; pecíolo 0,2-1,1 cm compr.; raque, 0,5-1,2 m compr., 17-62 pinas de cada lado, distribuídas irregularmente ao longo da raque e dispostas em mais de um plano. Inflorescência interfoliar, ramificada; pedúnculo 12-28 cm compr.; profilo 9-19 cm compr.; bráctea peduncular espinhenta, tomentosa, com $18-57 \mathrm{~cm}$ compr.; raque $10-18 \mathrm{~cm}$ compr.; $10-25$ ráquilas, até $15 \mathrm{~cm}$ compr. Flores amarelo-creme, masculinas $0,3-$ $1,0 \times 0,02-0,08 \mathrm{~cm}$, femininas $0,5-1,2 \times 0,04-0,08 \mathrm{~cm}$ na mesma inflorescência, $0,7-1,3 \times 0,7-1,4 \mathrm{~cm}, 3$ pétalas e 3 sépalas. Frutos pretos ou purpúreos quando maduros, 1-2,7 cm diâm., globosos; epicarpo glabro, mesocarpo suculento; endocarpo ósseo, 0,7-2,0 cm diâm., 3 poros de germinação e uma única semente; endosperma homogêneo. Eófilo bífido.

Nomes populares: tucum, jacum, tucum-bravo, tucumamarelo, tucum-do-brejo, tucum-piranga, uva-da-terra, coco-de-natal, marajá-iba.

Material examinado: BRASIL, SANTA CATARINA, Biguaçu, Sorocaba do Sul, 6.VII.2010, A. Stival-Santos, S. Silveira \& D. Meyer 3196 (FURB); Blumenau, RPPN Bugerkopf, 31.III.2013, L. A. Funez 1936 (FURB); Brusque, Azambuja, 1.X.1948, R. Reitz 2248 (HBR), 7.XVIII.1947, R. Reitz 1872 (HBR); Gaspar, Gasparinho, 15.X.2009, A Stival-Santos \& E. Legal 1045 (FURB); Guabiruba, Sterntal (Aymoré), 8.X.2004, F. Bosio s $/ n^{\circ}$ (FURB 2694); Ibirama, Horto Florestal I. N. P, 2.XI.1953, R. Reitz \& R. M. Klein 1127 (HBR); Itajaí, Cordeiros, 9.X.1959, R. Reitz \& R. M. Klein 9174 (HBR); Orleans, Rio Novo, 30.IV.1992, V. Citadini-Zanette \& A. J. Aguiar 1412 (CRI), Parque Estadual da Serra Furada, 3.II.2016, G. A. Elias \& P. T. Padilha 14 (CRI); Piçarras, Bela Vista, 10.X.2009, S. Dreveck \& F. E. Carneiro 1120 (FURB); Sombrio, Sanga da Areia, 31.X.1959, R. Reitz, \& R. M. Klein 9328 (HBR). Material adicional examinado: BRASIL, RIO GRANDE DO SUL, Candelária, morro Três Irmãos, 25.VII.2012, $K$. Soares \& L. Witeck 29 (HDCF). 


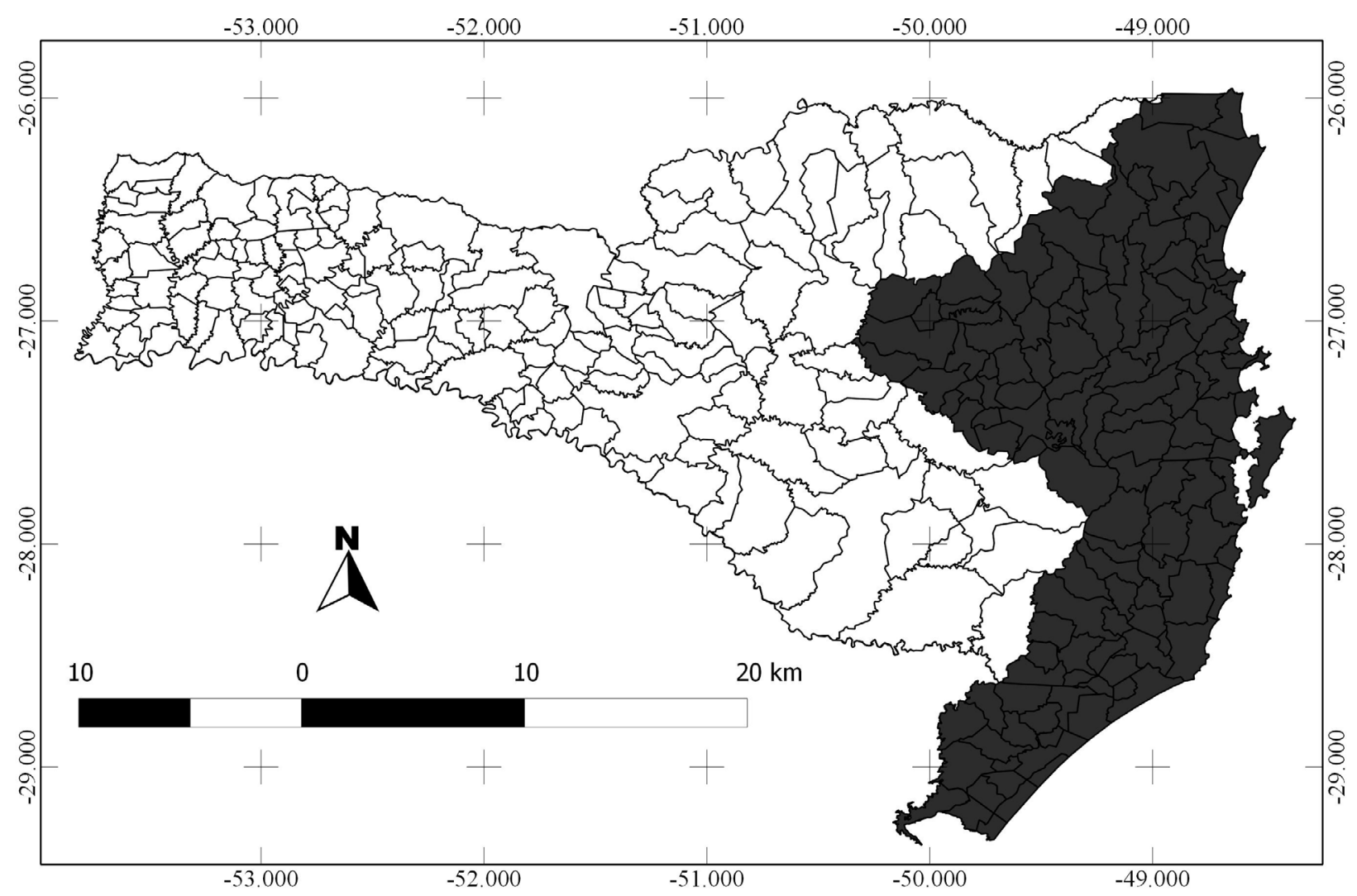

Fig. 4. Mapa de distribuição da espécie Bactris setosa Mart. em Santa Catarina.

Espécie esciófita e seletiva higrófita que tem preferência por solos úmidos e está distribuída desde o sul da Bahia até o Rio Grande do Sul (Lorenzi et al. 2010, Soares et al. 2014). Em Santa Catarina ocorre entre o extremo norte e extremo sul, presente também no Vale do Itajaí, com distribuição altitudinal variando entre 5 e $400 \mathrm{~m}$ (Reitz 1974).

Tem uso difundido para variedades de cordoaria, por meio de suas folhas, pode ser utilizada para a fabricação de utensílios de caça e pesca, bem como objetos domésticos. Possui polpa agradável e amêndoa comestível (Reitz 1974, Lorenzi et al. 2010, Soares et al. 2014).

4 Butia (Becc.) Becc., Agric. Colon. 10: 489. 1916. Lectótipo: B. capitata (Mart.) Becc. Agric. Colon. 10: 504. 1916.

O gênero está incluído na subfamília Cocosoideae, tribo Cocoeae (Reitz 1974). Trata-se de um gênero monofilético, ocorrente na América do Sul, com 19 espécies, sendo 11 endêmicas. As plantas apresentam porte pequeno a moderado, são solitárias ou cespitosas, podendo ter caule subterrâneo, de altura moderada (Lorenzi et al. 2010, Leitman et al. 2015).

Atualmente encontra-se em perigo e risco de extinção em decorrência da expansão agrícola, da pecuária, da extração e comercialização ilegal e reflorestamento com outras espécies vegetais (Soares \& Witeck 2009, Hoffmann et al. 2014, Nazareno \& Reis 2014).
4.1 Butia catarinensis Noblick \& Lorenzi, Fl. Brazil. Arec: 164. 2010.

Holótipo: BRASIL. SANTA CATARINA: Barra do Sul, 29.X.2009, H. Lorenzi \& K. Soares 6760 (Holótipo, HPL!).

(Figs. 5A-D, 6)

Estipe 0,2-2,8-(4) m alt., 10-49 cm. diâm. Folhas pinadas, 9-32 contemporâneas; bainha 35-127 × 5-13 cm; pseudopecíolo 16-68 $\times 1,5-2,7 \mathrm{~cm}$, fibras e dentes fortes na sua margem; raque $65-200 \mathrm{~cm}$ compr., $42-60$ pares de pinas; pinas distribuídas uniformemente e inseridas em um ou mais planos pouco discrepantes, formando um "V" sobre a raque, as partes medianas da raque 30-69 $\times$ 1,0-2,5 cm. Inflorescência interfoliar; pedúnculo 26-72 $\mathrm{cm} \times 1,5-2,0 \mathrm{~cm}$; profilo $18-37 \times 3,0-5,5 \mathrm{~cm}$; bráctea peduncular glabra ou levemente coberta por tomento, ápice apiculado, 62-113 cm compr., parte expandida 30-72 × 5-15 cm; eixo da inflorescência 31-64 cm compr.; raque $66-189 \mathrm{~cm}$ compr., 29-137 ráquilas 9-47 cm compr. Flores amarelas, arroxeadas, esverdeadas na mesma inflorescência; estaminadas 6-11 mm compr.; pistiladas 4-7(-10) mm compr. Frutos amarelos, alaranjados ou avermelhados quando maduros, $1,2-2,1 \times 1,0-2,7 \mathrm{~cm}$, perianto persistente; mesocarpo amarelo, endocarpo estreito-ovoide, ápice sem bico ou qualquer protuberância, 1,1-1,5 × 0,6-1,3 cm; sementes, 1-2(-3); endosperma homogêneo. Eófilo simples. 

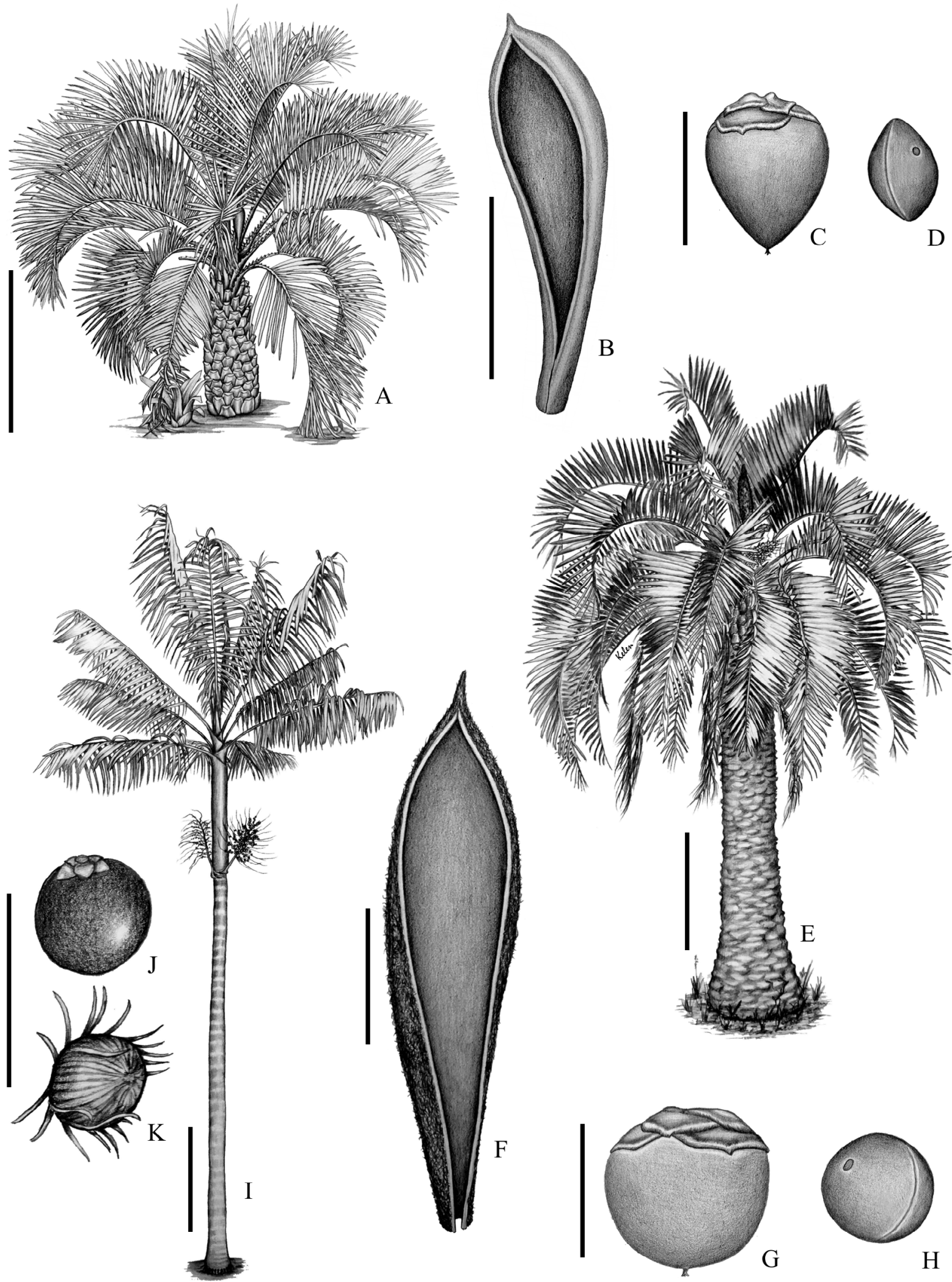

Figs. 5 A-K. A-D. Butia catarinensis (G. A. Elias 16). A. hábito; B. bráctea peduncular externamente glabra; C. fruto; D. endocarpo. E-H. Butia eriospatha (K. Soares \& L. Witeck 33). E. hábito; F. bráctea peduncular externamente lanuginosa; G. fruto; H. endocarpo. I-K. Euterpe edulis (K. Soares 30). I. hábito; J. fruto; K. endocarpo. Barras: Figs. A, E, I =1 m; Figs. B, F $=20 \mathrm{~cm}$. C; Figs. D, G, H, J $=2 \mathrm{~cm}$. 


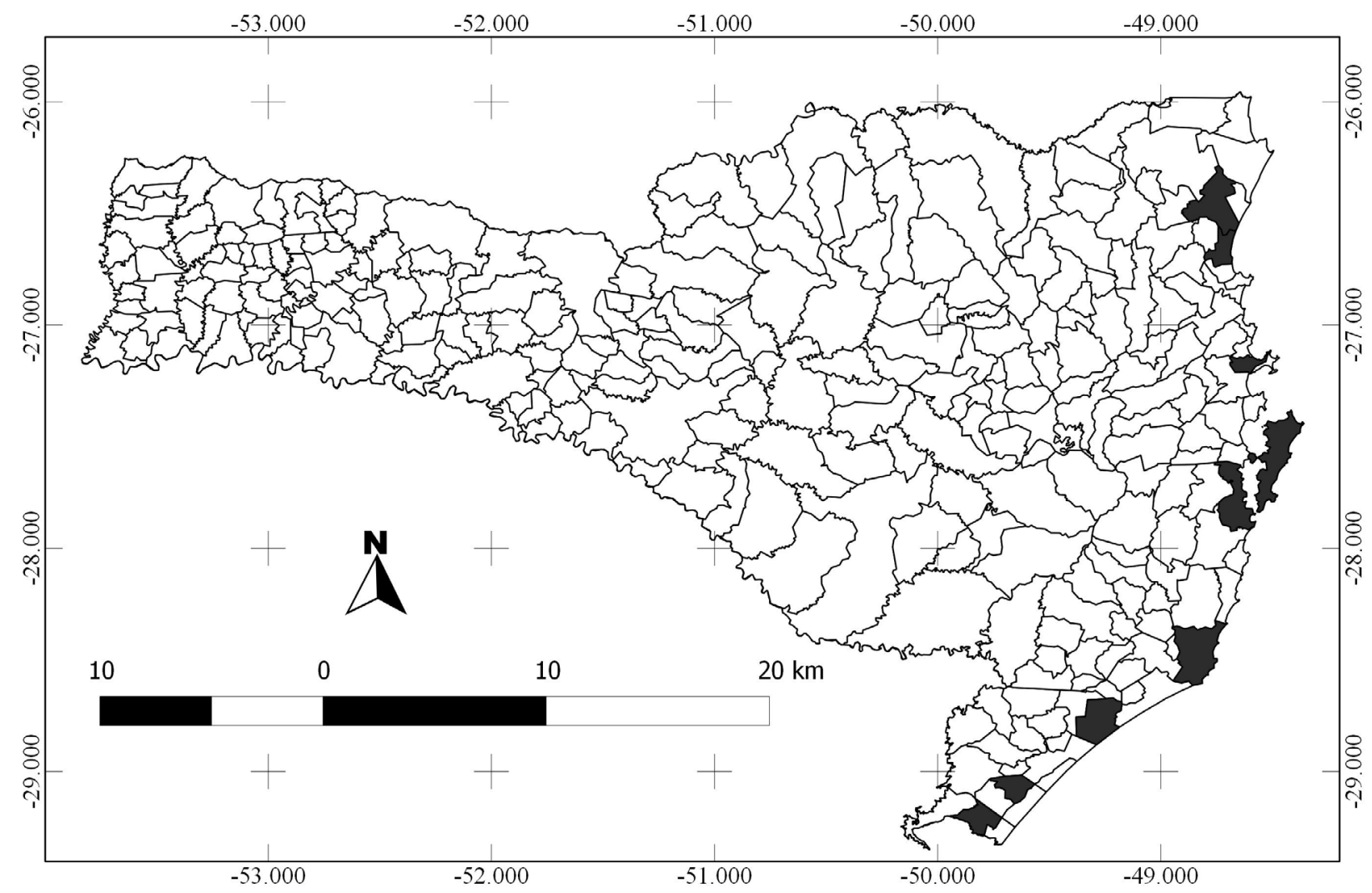

Fig. 6. Mapa de distribuição da espécie Butia catarinensis Noblick \& Lorenzi em Santa Catarina.

Nomes populares: butiá, butiá-azedo, butiá-da-praia. Material examinado: BRASIL, SANTA CATARINA, Balneário Rincão, 20.II.2016, G. A. Elias 16 (CRI); Barra do Sul, 10.II.1953, R. Reitz 5634 (HBR); Barra Velha, Itajuba, 11.I.1951, R. Reitz 3803 (HBR); Itajuba, 11.I.1951, R. Reitz 3757 (HBR), 11.I.1951, R. Reitz 3739 (HBR), $R$. Reitz 3804 (HBR); Bombinhas, Bombas, 25.IV.1971, $R$. Reitz 7452 (HBR); Içara, Balneário Rincão, 9.XII.2010, A. Korte 5390 (FURB); Laguna, 19.IX.1951, R. Reitz \& R. M. Klein 178 (HBR), 22.XII.1951, R. Reitz \& R. M. Klein 180 (HBR), 20.IX.1951, R. Reitz. \& R. M. Klein 2 (HBR); Palhoça, Campo do Maciambu, 24.IX.1953, R. Reitz \& R. M. Klein 1026 (HBR), Parque Estadual do Tabuleiro, 2.XII.2010, A. Korte 5390 (FURB); São Francisco do Sul, Parque Estadual do Acaraí, 29.XI.2010, A. Korte \& A. L. Gasper 5267 (FURB), Praia do Ervino, 30.III.2007, L. Sevegnani, \& A. L. Gasper 113 (FURB); Sombrio, 6.II.1946, R. Reitz, 1419 (HBR), 7.I.1949, R. Reitz 2965 (HBR), Rio Novo, 7.VII.1959, R. Reitz \& R. M. Klein 8903 (HBR).

Espécie heliófita, característica dos solos arenosos e rochosos, bem como das dunas fixas, podendo alternar entre os campos litorâneos e a vegetação arbustiva da restinga, formando pequenos agrupamentos chamados de butiazais. Pode ser observada de norte a sul pelo litoral catarinense, com distribuição irregular, variando entre 5 e $20 \mathrm{~m}$ de altitude (Reitz 1974, Lorenzi et al. 2010).
Diferencia-se de Butia odorata (Barb.Rodr.) Noblick \& Lorenzi, que ocorre no litoral do RS até o Uruguai, pelo menor porte, dificilmente ultrapassando os dois metros de altura, pelos frutos menores e mais alongados, pela forma do endocarpo que são oblonga ou estreito-ovoide e diferenças na bráctea peduncular da inflorescência, que se alarga em direção ao ápice, abruptamente terminando em um ápice apiculado (Lorenzi et al. 2010, Soares et al. 2014).

As folhas podem servir como cobertura para construções rústicas e para a indústria de papel e celulose (Reitz 1974). É largamente empregada, nos municípios onde ocorre, especialmente como planta alimentícia, sendo a polpa empregada para fabricação de licores, doces, sorvetes ou mesmo in natura (Coradin et al. 2011).

4.2 Butia eriospatha (Mart. ex Drude) Becc., L'Agric. Colon. 10: 496. 1916.

Tipo: BRASIL, RIO GRANDE DO SUL: sd., A.F.M. Glaziou 8059 (lectótipo, K!).

(Figs. 5E-H, 7)

Estipe 2-12 m alt., 20-50 cm diâm. Folhas pinadas, 20-39 contemporâneas; bainhas 113-156 cm compr.; pseudopecíolo fibroso e denteado, com $68 \mathrm{~cm}$ compr.; raque 1,3-2,1 m compr., 73-99 pinas regularmente distribuídas, dispostas em "V" sobre a raque; pinas medianas ca. $61 \times$ $2,5 \mathrm{~cm}$. Inflorescência interfoliar; pedúnculo $46-92 \mathrm{~cm}$ compr.; profilo com $36-52 \times 4,0-6,0 \mathrm{~cm}$; bráctea peduncular 


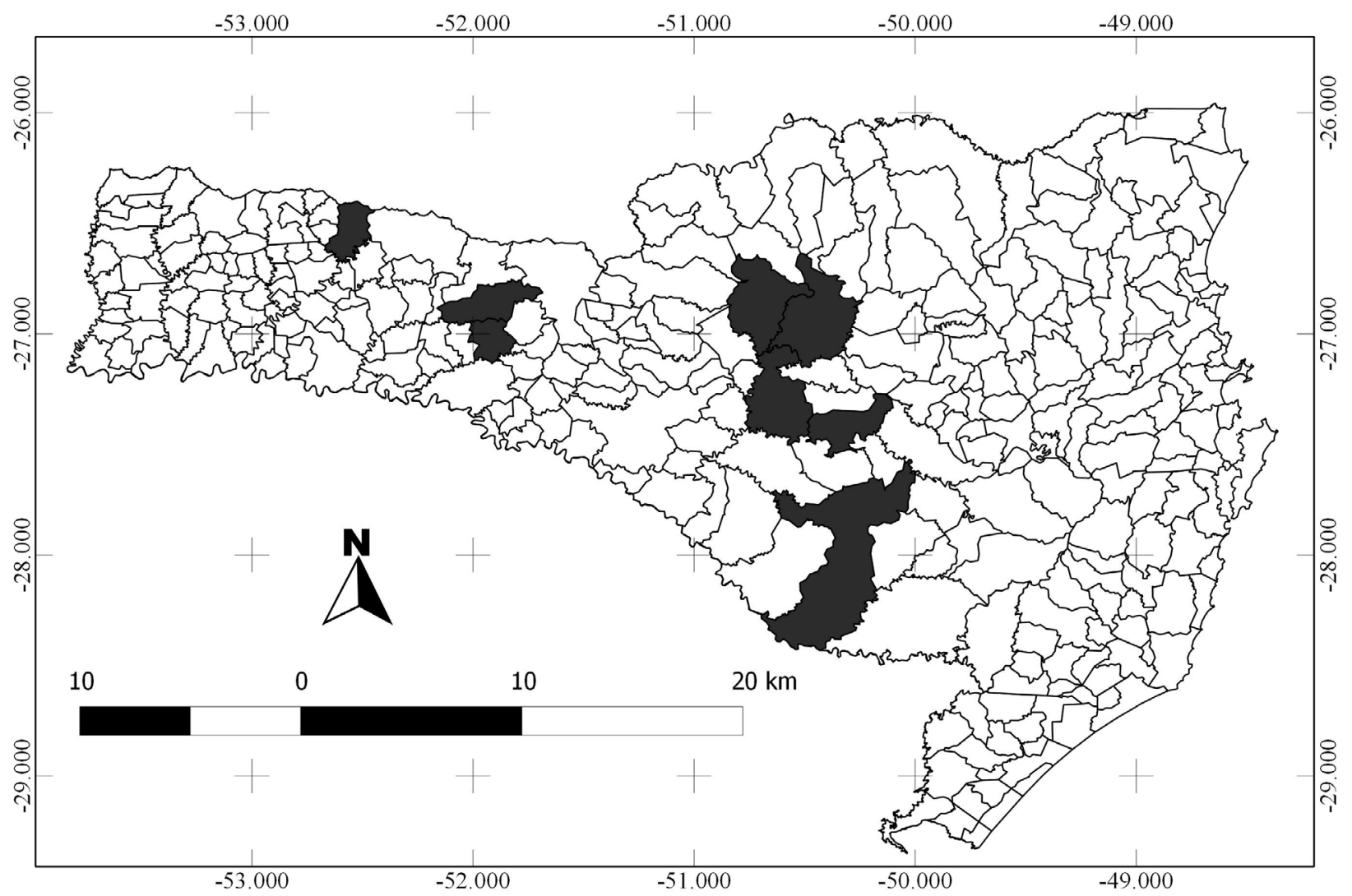

Fig. 7. Mapa de distribuição da espécie Butia eriospatha (Mart. ex Drude) Becc. em Santa Catarina.

lenhosa, revestida por um denso indumento lanuginoso de cor castanho-avermelhada, 117-139 cm compr., parte expandida 80-105 × 14-21 cm; eixo da inflorescência $75-106 \mathrm{~cm}$ compr., 50-129 ráquilas, as da parte mediana da raque $10-47 \mathrm{~cm}$ compr. Flores amarelas; estaminadas ca. $5 \mathrm{~mm}$ compr.; pistiladas $5-11 \mathrm{~mm}$ compr. na mesma inflorescência. Frutos globosos 1,8-2,4 × 1,5-3,2 cm; mesocarpo amarelo, carnoso, pouco fibroso; endocarpo arredondado contendo 1-3 sementes 1,3-1,7 × 1,1-2,1 cm; endosperma homogêneo. Eófilo simples.

Nomes populares: butiá, butiá-da-serra, butiazeiro, butieiro, macuma, butiá-veludo, butiá-branco.

Material examinado: BRASIL, SANTA CATARINA, Lages, Bairro Conta Dinheiro, 30.X.2006, H. Lebkuchen $s / n^{\circ}$ (LUSC 73, 74 e 75), Campus UDESC, 24.IV.2015, G. A. Elias \& R. Bortoluzzi 1415 (CRI); Iraní, Campos de Iraní, 28.XII.1963, R. Reitz \& R. M. Klein 16461 (HBR), Ponte Serrada, 3.I.1957, B. Smith \& R. Reitz 9835 (HBR), Ponte Alta, 9.II.1951, R. Reitz 3820 (HBR); São Domingos, Parque Estadual das Araucárias, 18.IV.2009, A. StivalSantos \& S. Silveira 1578 (FURB).

Material adicional examinado: BRASIL, RIO GRANDE DO SUL, Nova Prata, cultivado, 26.VIII.2012, K. Soares 30 (HDCF).

Espécie heliófita e com características de higrófita, ocorre nos estados do Paraná, Santa Catarina e Rio Grande do Sul, onde muitas vezes está associada à Floresta Ombrófila Mista. Em Santa Catarina apresenta distribuição irregular, variando entre 700 e $1.000 \mathrm{~m}$ de altitude, mas abundante em determinadas áreas, forma associações densas, principalmente, no município de Lebon Régis (Reitz 1974, Lorenzi et al. 2010, Soares et al. 2014).

A espécie se enquadra na categoria VU (Vulnerável), pela IUCN, tendo suas ameaças representadas pelo reflorestamento com espécies exóticas, pecuária intensiva e perda de habitat pela expansão urbana (Noblick 1998).

Por possuir hábito vistoso é muito utilizada para fins paisagísticos sendo comumente encontrada em praças e jardins. Tem seu uso destinado também para fabricação de chapéus, cestas e demais utensílios fibrosos (Reitz 1974). Seus frutos possuem polpa utilizada na fabricação de muitos produtos alimentícios, incluindo sucos, geleias, licores e sorvetes (Coradin et al. 2011).

5. Euterpe Mart., Hist. Nat. Palm. 2: 28. 1823, emend. 3: 165.1837.

Tipo: E. oleracea Mart., Hist. Nat. Palm. 2: 29. 1824.

O gênero está incluído na subfamília Arecoideae, tribo Areceae, subtribo Euterpeinae. As palmeiras deste gênero são monóicas, de pequeno a médio porte, sem espinhos, solitárias ou cespitosas; ocorrem na América Central, Caribe e América do Sul (Reitz 1974, Lorenzi et al. 2010). Possui cinco espécies e nenhuma delas endêmica do Brasil (Leitman et al. 2015). 
5.1 Euterpe edulis Mart., Hist. Nat. Palm. 2(2): 33- 34, t.32. 1824

Tipo: BRASIL. BAHIA: Almada, C. Martius s.n. (Isótipo, $\mathrm{P}$ ).

$$
\text { (Figs. 5I-K, 8) }
$$

Estipe solitário, 3-20 m alt., 10-18 cm diâm., liso, com um palmito verde ou alaranjado formado pelas bainhas das folhas, 1-2,1 m compr. Folhas pinadas, 8-17 contemporâneas, 1,2-2,9 m compr.; bainha 1-1,8 m; pecíolo 11-57 cm compr., margem lisa, coberto com tomento escamoso achatado; raque 1,5-3,7 m compr., 40-78 pares de pinas, distribuídas regularmente e num mesmo plano ao longo da raque, com as extremidades pendentes. Inflorescências infrafoliares, ramificadas em nível de primeira ordem; bráctea peduncular papirácea, $50-88 \mathrm{~cm}$; ráquilas $40-117,25-76 \mathrm{~cm}$ compr. Flores unissexuadas, ambas na mesma inflorescência; estaminadas 5-7 mm; pistiladas 3-5 mm. Frutos globosos, 1-2 cm diâm., roxo-escuros ou pretos; mesocarpo fino, fibro-carnosos; endocarpo duro, 0,5-1,6 cm diâm., uma semente. Eófilo palmado.

Nomes populares: içara, palmito-doce, palmito-juçara, juçara, palmiteiro, ensarova, ripeira.

Material examinado: BRASIL, SANTA CATARINA, Águas Mornas, Vargem Grande, 19.V.2010, A. StivalSantos; E. Legal \& S. Silveira 2772 (FURB); Brusque, Azambuja, 24.X.1947, R. Reitz s/n ${ }^{\circ}$ (HBR 2690); Criciúma, SANTEC Resíduos, 22.VIII.2007, B. Wessler \& B. Alberton $s / n^{\circ}$ (CRI 7976); Corupá, 27.IX.2008, J. Correia $s / n^{\circ}$ (LUSC 2157 e 3903); Florianópolis, 29.VII.2006, S. B. Mesquita, $s / n^{o}$ (LUSC 76), 2.XI.2006, R. J. Eller Junior $s / n^{\circ}$. (LUSC 77); Itapoá, Reserva Volta Velha, 19.XII.2015, G. A. Elias et al. 6 (CRI); Morro Grande, Rio Morto, 20.X.2009, M. Verdi, A. L. Tomazi \& Z. Klemz 2883 (FURB); Rodeio, 8.XII.2013, L. A. Funez 2396 (FURB); Rio do Sul, Serra do Matador, 26.VI.1959, R. Reitz \& R. M. Klein 8889 (FURB); São Bonifácio, Rio Poncho, 2.VII.2010, M. Verdi, B. Burkhardt \& G. Klemz 5167 (FURB); Siderópolis, Belvedere Baixo, 28.I.2010, M. Verdi, N. L. Souza \& D. H. Klettenberg 3440 (FURB).

Material adicional examinado: BRASIL, RIO GRANDE DO SUL, Novos Cabrais, 28.VII.2012, K. Soares \& L. Witeck 33 (HDCF).

Espécie ciófila, mesófita ou levemente higrófita, ocorre do sul da Bahia e Minas Gerais até o Rio Grande do Sul, presente também nos estados de GO, DF, MS, SP, PR e $\mathrm{SC}$ além de Argentina e Paraguai. Em Santa Catarina é amplamente distribuída, sendo considerada dominante e mais abundante do segundo estrato arbóreo da Floresta Atlântica, com variação altitudinal entre 20 e 650 m (Reitz 1974, Lorenzi et al. 2010).

Segundo os critérios da IUCN, se enquadra na categoria VU(Vulnerável), pois além de seu habitat estar ameaçado pela expansão urbana, pela pecuária e agricultura, historicamente, vêm sofrendo com a predação indiscriminada do palmito, uma vez que a espécie não rebrota após o corte.

Suas folhas são utilizadas para cobertura de construções rurais e utensílios fibrosos, assim como planta forrageira. Embora tenha a maior parte do seu uso destinado à indústria alimentícia, possui potencial paisagístico e industrial (Reitz 1974).

É a espécie com maior número de trabalhos indexados em bases de dados eletrônicas até o ano de 2013 sobre todas as palmeiras catarinenses, com 139 trabalhos, perfazendo aproximadamente $50 \%$ da produção científica acerca da família Arecaceae no Estado (Elias et al. 2015). Representa uma das espécies com maior Valor Potencial de Exploração Sustentável da Mata Atlântica no sul do Brasil (Elias \& Santos 2016).

\section{Geonoma Willd., Sp. Pl. (Willdenow) 4 (1):}

174. 1805.

Lectótipo: G. simplicifrons Willd. Sp. Pl. 4: 594. 1805.

O gênero constitui um grupo monofilético pertencente à subfamília Arecoideae, tribo Geonomeae, e possui preferência por vegetação ombrófila, raramente ocorrendo em áreas abertas. As espécies florestais são sensíveis aos elevados graus de umidade e sombreamento, portanto, tendem a desaparecer a medida com que seu habitat é perturbado (Lorenzi et al. 2010).

Em recente revisão do gênero, Henderson (2011) confere 68 espécies, sendo 12 ainda não descritas pela ciência, e a Lista de Espécies da Flora do Brasil cita 25 espécies nativas, sendo 7 endêmicas (Leitman et al. 2015).

\subsection{Geonoma elegans Mart., Hist. Nat. Palm. 2:}

144. t. 18 A. 1826

Tipo: BRASIL. s. loc., s.d., Riedel 733 (Holótipo G, perdido, Neótipo NY).

$$
\text { (Figs. 9A, B, 10) }
$$

Estipes múltiplos ou ocasionalmente simples, 1,5-3,0 $\mathrm{m}$ alt., 0,7-1,3 cm. diâm. Folhas geralmente inteiras ou pinadas; bainha 13-25 × 5,0-9,0 cm; pecíolo $60 \mathrm{~cm}$ compr.; raque $40-50 \mathrm{~cm}$ compr., contendo 3 pares de pinas ou 3 pinas inteiras intercaladas com pinas mais estreitas em cada lado da raque ou então com pinas inteiras nos dois lados da raque; pinas longo-acuminadas com 0,35-1,10 m compr., plurinervadas. Inflorescência espiciforme; profilo 10-20 cm compr.; bráctea peduncular poucos milímetros menores, encoberta pelo profilo; 20-25 cm compr., eixo da inflorescência $40 \mathrm{~cm}$ compr. Flores avermelhadas com os alvéolos florais distribuídos de forma espiralada em quase toda sua extensão. Frutos ovoides, levemente apiculados no ápice, lisos, 0,7-0,9 × 0,7 cm, epicarpo de cor negra ou roxo-escura quando maduros, mesocarpo pouco fibroso; endocarpo 1,5-2,9 × 1,0-1,8 cm, contendo uma única semente. Eófilo bífido.

Nomes populares: aricanguinha, aricanga-de-bengala. Material examinado: BRASIL, SANTA CATARINA, 


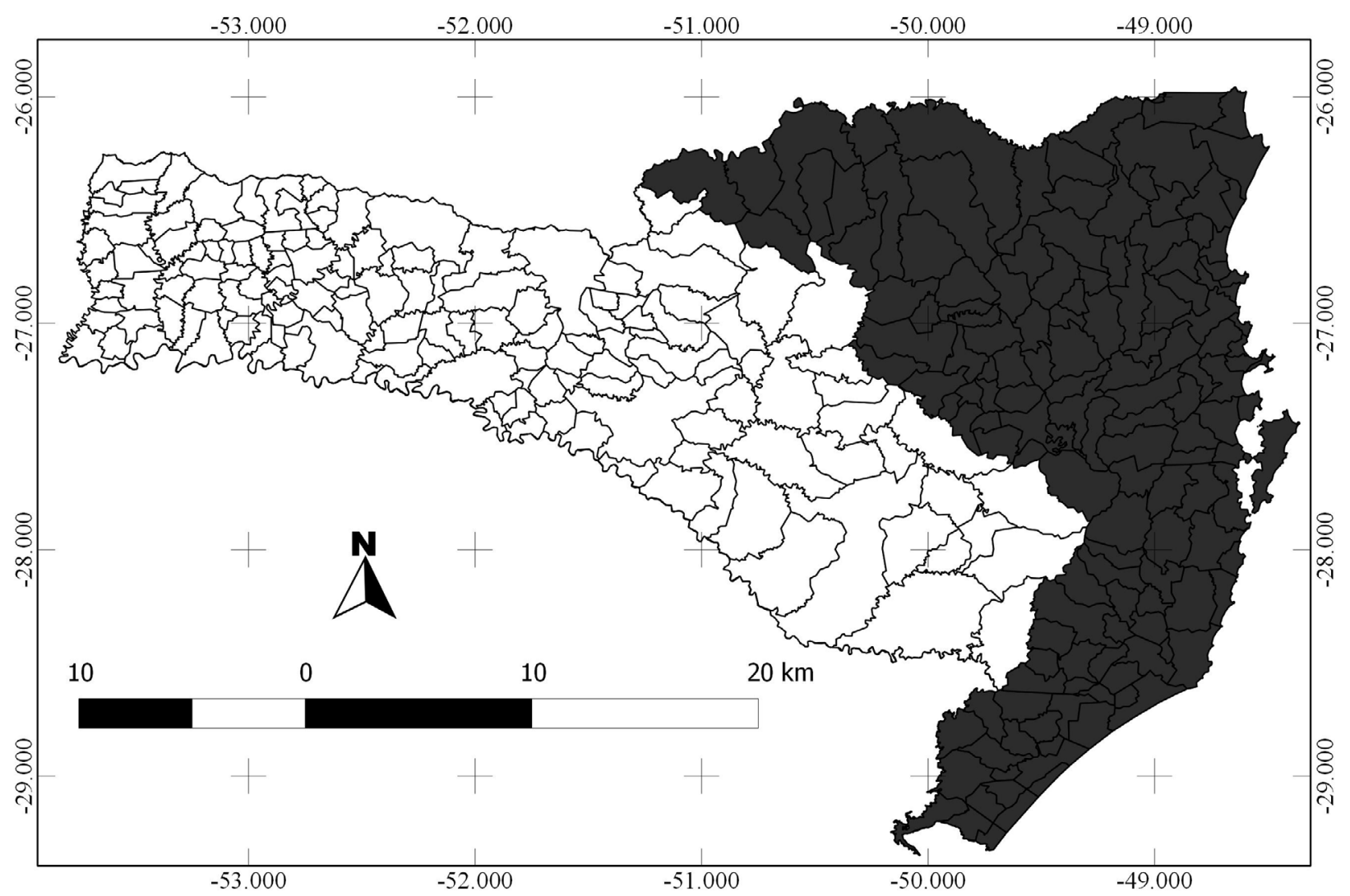

Fig. 8. Mapa de distribuição da espécie Euterpe edulis Mart. em Santa Catarina.

Barra Velha, Medeiros, 28.IX.1946, R. Reitz 1703 (HBR); Camboriú, Rio do Meio, 11.XI.2010, A. Korte \& A. Kniess 4946 (FURB); Garuva, Porto das Canoas, 21.II.1952, $R$. Reitz 4402 (HBR), Mina Velha, 8.X.2009, S. Dreveck \& F. E. Carneiro 1100 (FURB), Sol Nascente, 30.IX.2009, A. L. Gasper, T. J. Cadorin \& J. Schmitt 2431 (FURB); Ilhota, 25.I.2014, L. A. Funez, \& A. E. Zermiani 2436 (FURB); Itajaí, Morro da Ressacada, 9.II.1954, R. Reitz \& R. M. Klein 1530 (HBR), 29.III.1956, R. Reitz \& R. M. Klein 2921 (HBR); Itapoá, Reserva Volta Velha, 19.XII.2016, G. A. Elias 5 (CRI), Morro da Fazenda, 3.III.1954, R. Reitz \& R. M. Klein 1684 (HBR), Rio Sai-Guaçu, 16.IX.2009, S. Dreveck \& F. E. Carneiro 1059 (FURB); Joinville, 12.I.1951, R. Reitz 3814 (HBR); Luís Alves, Bairro Serafim, 22.I.1948, R. Reitz 2008 (HBR); Massaranduba, Guarani, 7.III.2011, A. Korte 6104 (FURB); Navegantes, Leiteiro, 14.IX.2009, A. Stival-Santos, E. Legal \& S. Silveira 834 (FURB); São Francisco do Sul, Vila da Glória, 20.IV.2013, L. A. Funez, K. Kelmmelmeier \& A. E. Zermiani 2109 (FURB); Schroeder, Rancho Bom, 19.II.2010, S. Dreveck \& F. E. Carneiro 1813 (FURB).

Espécie seletiva esciófita e higrófita, representativa em florestas altas e sombreadas, ocorrendo do Espirito Santo a Santa Catarina, pela encosta Atlântica, em densas populações, tendo possivelmente seu limite austral no Vale do Itajaí (Reitz 1974).

No município de Garuva e Guaramirim, Reitz (1974) constatou densas populações com 44 a 49 exemplares em
$100 \mathrm{~m}^{2}$, onde a densidade é diretamente proporcional à umidade do solo. Aparece em áreas bem drenadas, desde o nível do mar até 700 metros, sendo sensível a perturbações na vegetação (Lorenzi et al. 2010).

Possui potencial paisagístico e é utilizada na confecção de arranjos florais. Por ser uma espécie tolerante à sombra, é cultivada em vasos para interiores e jardins sombreados, além disso, podem ser usadas em coberturas de construções rústicas (Reitz 1974, Lorenzi et al. 2010).

6.2 Geonoma gamiova Barb.Rodr. Contr. Jard. Bot. Rio de Janeiro 6: t. 37. 1907. Suppl. Sert. Palm. Brasil. Tipo: Ilustração designada como lectótipo: BRASIL: SANTA CATARINA, Blumenau, Anon. sn. (not known). Geonoma meriodionalis Lorenzi, Brazil. Fl. Arec.: 240. 2010.

(Figs. 9C-G, 11)

Estipes múltiplos ou solitário, profundamente anelado, 0,8-6 m alt., 2-3,5 cm diâm., anéis espaçados por 1,3-8,0 $\mathrm{cm}$, quando a planta é cespitosa produz poucos estipes. Folhas pinadas, 3-22 contemporâneas; bainha 13-38 $\times$ 5,3-9,0 cm; pecíolo 24-56 × 0,3-0,9 cm; raque 40-67 cm compr., 3-17 pinas de cada lado, pode apresentar número diferente de pinas em cada lado, largura 1-14 cm, 0,5-3,9 $\mathrm{cm}$ de distância entre elas. Inflorescências interfoliares, podendo tornar-se infrafoliar no período de maturação dos frutos, ramificadas em nível de segunda ordem, envolvidas 


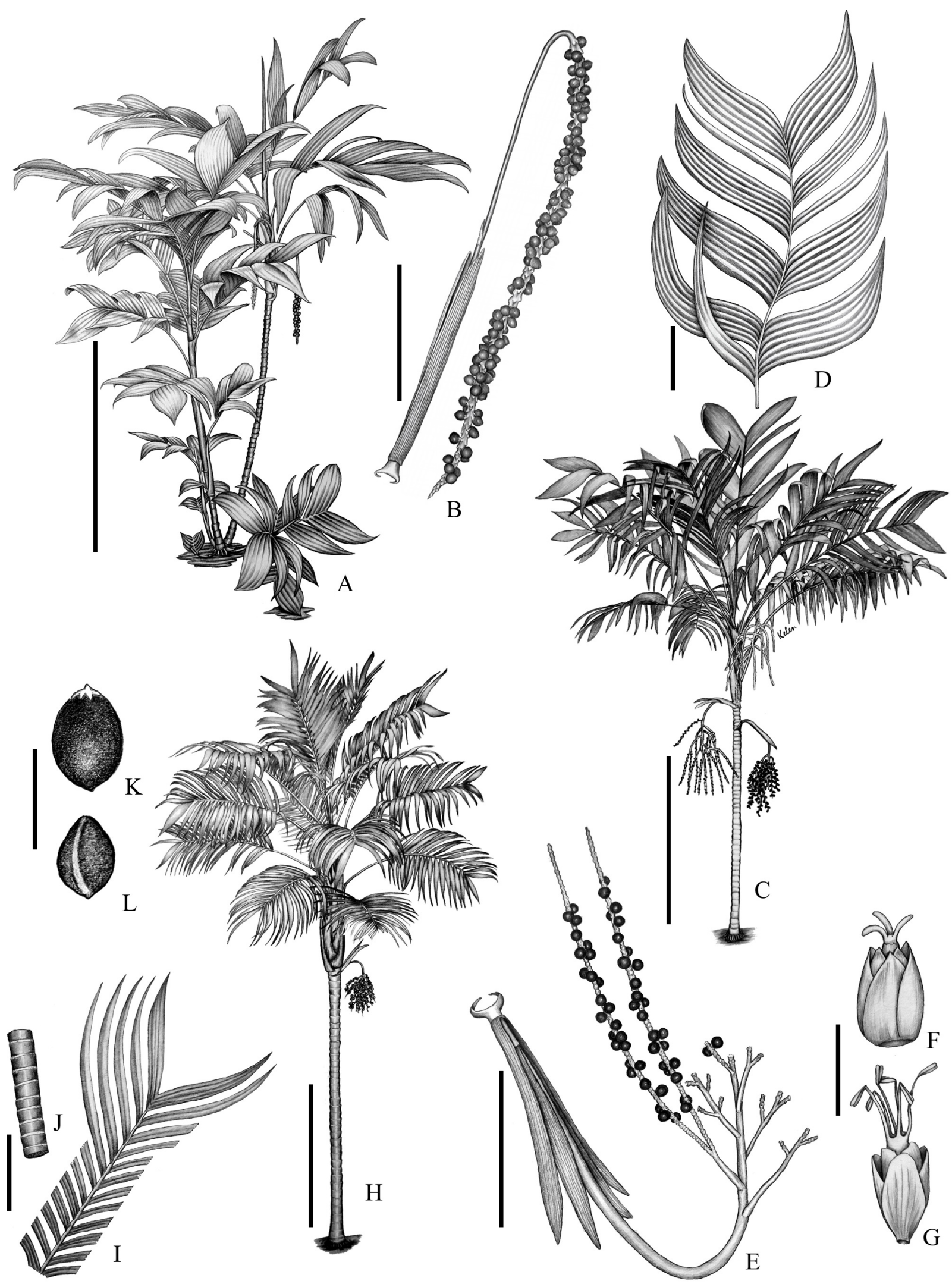

Figs. 9A-L. A, B. Geonoma elegans (G. A. Elias et al. 5). A. hábito; B. infrutescência. C-G. Geonoma gamiova (K. Soares \& H. Büneker 34). C. hábito; D. Folha; E. infrutescência; F. flor pistilada G. flor estaminada. H-L. Geonoma schottiana (K. Soares 36). H. hábito; I. detalhe da folha; J. detalhe do estipe; K. fruto; L. endocarpo. Barras: Figs. A, C, H=1 m; Figs. B, D, E, I; Fig. J $=10 \mathrm{~cm}$; Figs. F, G $=2 \mathrm{~mm} ; \mathbf{F i g s . ~}$, L $=1 \mathrm{~cm}$. 
por duas brácteas papiráceas, frisadas externamente, ambas caducas após a antese; profilo 12-27 × 1,7-3,8 $\mathrm{cm}$; bráctea peduncular 14-19 × 1,1-3,9 cm; pedúnculo $11-32 \times 0,8-1,7 \mathrm{~cm}$; raque da inflorescência 6-20 × 0,4$0,7 \mathrm{~cm}, 5-32$ ráquilas, as basais geralmente ramificadas; ráquilas 10-48 × 0,3-0,7 cm. Alvéolos florais dispostos espiraladamente ao redor das ráquilas. Flores, estaminadas com 4,5 mm compr.; pistiladas com 3,2 mm compr. na mesma inflorescência. Frutos ovoides com 1,1-1,7 × 0,3$1,4 \mathrm{~cm}$, pretos quando maduro; endocarpo, superfície lisa, 0,5-1,2 cm diâm., marrom-avermelhado, uma semente, endosperma homogêneo. Eófilo bífido.

Nomes populares: gamiova, guaricanga-de-folha-larga, palheira-de-folha-larga, ouricana-de-folha-larga, aricanade-folha-larga, uricana-de-folha-larga.

Material examinado: BRASIL, SANTA CATARINA, Garuva, Monte Crista, 15.XI.2005, F. C. S. Vieira 1390 (JOI); Governador Celso Ramos, Jordão, 18.X.1971; Grão Pará, Barra do Rio Meio, 14.IV.2010, M. Verdi et al. 4423 (FURB); Guaramirim, 10.XI.2008, L. Sevegnani s/ $n^{\circ}$ (JOI 8341); Itapoá, Reserva Volta Velha, 30.VII.1992, V. Citadini-Zanette et al. 1484 (CRI), 19.XII.2015, G. A. Elias et al. 3 (CRI); Luís Alves, Braço Joaquim, 7.I.1955, R. Reitz \& R. M. Klein 2358 (HBR); Meleiro, 1.II.1944, R. Reitz 446 (HBR); Orleans, Rio Novo, 15.X.1992, V. Citadini-Zanette \& R. Santos 1463 (CRI), Parque Estadual da Serra Furada, 11.IV.2015, G. A. Elias 7 (CRI); São Bento do Sul, APA Rio Vermelho, 14.X2010, S. Dreveck \& M. Verdi 2518 (FURB); Siderópolis, Jordão, 9.X.2007, M. R. Pasetto, $s / n^{o}$ (CRI 7583); Turvo, 26.III.2008, J. G. Cemin $s / n^{\circ}$ (CRI 7888).

Material adicional examinado: BRASIL, RIO GRANDE DO SUL, Riozinho, próximo ao Pico da Canastra, 28.VIII.2012, K. Soares \& H. Büneker 34 (HDCF 6272).

Espécie seletiva esciófita e mesófita, ocorre desde o Rio de Janeiro até o Rio Grande do Sul, na Floresta Atlântica. Em Santa Catarina apresenta ampla distribuição em densas populações, desde o norte do Estado, passando pelo Vale do Itajaí, em direção ao sul. Esta espécie não possui preferências especiais por tipos específicos de solo, ocorrendo desde 20 até 800 m de altitude (Reitz 1974, Soares et al. 2014).

As folhas de G. gamiova possuem utilizações na cobertura de casas rústicas, potencialidade no uso de trançados como cestos, balaios, peneiras, entre outros. Podem ser também utilizadas na ornamentação de ambientes internos e compor arranjos florais. E, após desidratadas, podem ser tingidas e utilizadas para decoração (Reitz 1974), além de ser considerada uma das plantas nativas do futuro para uso fibroso (Müller 2011).

Lorenzi et al. (2010) descreveu Geonoma meridionalis Lorenzi, afirmando a inexistência de uma obra princeps com a descrição de Geonoma gamiova Barb.Rodr., reiterando que o binômio seria um nomen nudum. Em contrapartida, Henderson (2011) desconsiderou totalmente G. gamiova e todas as espécies que não possuíam tipo em herbários, colocando assim G. meridionalis como sinônimo de G. pohliana Mart. Já o portal eletrônico "The Plant List" colocou G. gamiova como sinônimo de G. elegans, fato curioso, já que apresentam distintas características, especialmente quanto ao tipo de inflorescência, uma vez que em G. elegans ela é espiciforme, e em G. gamiova, paniculada. No presente trabalho considera-se o binômio G. gamiova como válido até que mais trabalhos sejam realizados, uma vez que, na ausência do material tipo em herbário, a ilustração pode ser considerada o tipo (McNeill et al. 2012), presente no protótipo, Tab. XXXVII (Barbosa Rodrigues 1907, Soares et al. 2014). Além disso, os autores deste artigo encontraram diferenças na distribuição dos alvéolos florais das ráquilas entre as coletas de G. gamiova e G. pohliana, sendo mais condensadas e uniformemente distribuídas em G. pohliana.

A espécie $G$. pohliana tem sido erroneamente citada para o estado de Santa Catarina (Leitman et al. 2015), provavelmente devido à sinonimização de G. gamiova proposta por Henderson (2011). O limite austral de distribuição de G. pohliana é no estado do Rio de Janeiro, ocorrendo, também, em Alagoas, Bahia, Ceará, Espirito Santo e Pernambuco segundo Henderson et al. (1995), entretanto, Lorenzi et al. (2010) cita sua ocorrência apenas para os estados da Bahia, Espírito Santo, Rio de Janeiro e São Paulo. Essa indefinição, quanto à ocorrência, indica a necessidade de uma revisão acerca da distribuição geográfica da espécie.

6.3 Geonoma schottiana Mart., Hist. Nat. Palm. 2: 143, t. 11 A. 1826 .

Tipo: BRASIL. RIO DE JANEIRO: s.d., H. Schott

4111 (Holótipo, M, n.v.).

(Figs. 9H-L, 12)

Estipe solitário, anelado, 1,0-8,0 m alt., 1,5-3,7 cm diâm., anéis distantes entre si por 1,2-8,5 cm. Folhas pinadas, 7-24 contemporâneas; bainhas 23-33 × 6,0$12 \mathrm{~cm}$; pecíolo $30-87 \times 0,5-1,2 \mathrm{~cm}$; raque $44-130 \mathrm{~cm}$ compr., 9-48 pinas estreitas, distribuídas regularmente ao longo da raque, em um plano e com largura mais ou menos uniforme, exceto em indivíduos jovens, que podem apresentar pinas com larguras variadas; pinas com uma nervura central e duas laterais, 11-67 ×0,4-3,2 cm, as da parte apical da folha até $11 \mathrm{~cm}$ largura. Inflorescências interfoliares, podendo tonar-se infrafoliares no período de maturação dos frutos, ramificadas ao nível de segunda ou terceira ordem, envolvidas por duas brácteas papiráceas, caducas após a antese; profilo 17-39 × 1,9-4,1 cm; bráctea peduncular 10-36 × 1,6-4,3 cm; pedúnculo 18-61 × 1-3 $\mathrm{cm}$; raque da inflorescência 15-22 cm compr., 13-68 ráquilas de $8-35 \times 0,3-0,5 \mathrm{~cm}$, as basais ramificadas. Alvéolos florais dispostos espiraladamente ao redor das ráquilas. Flores estaminadas $4,3 \mathrm{~mm}$ compr.; pistiladas com 3,1 mm compr. na mesma inflorescência. Frutos globosos, 0,9-1,7 × 0,3-1,6 cm, pretos quando maduros; endocarpo 0,6-1,5 cm diâm., superfície lisa, uma semente; endosperma homogêneo. Eófilo bífido. 


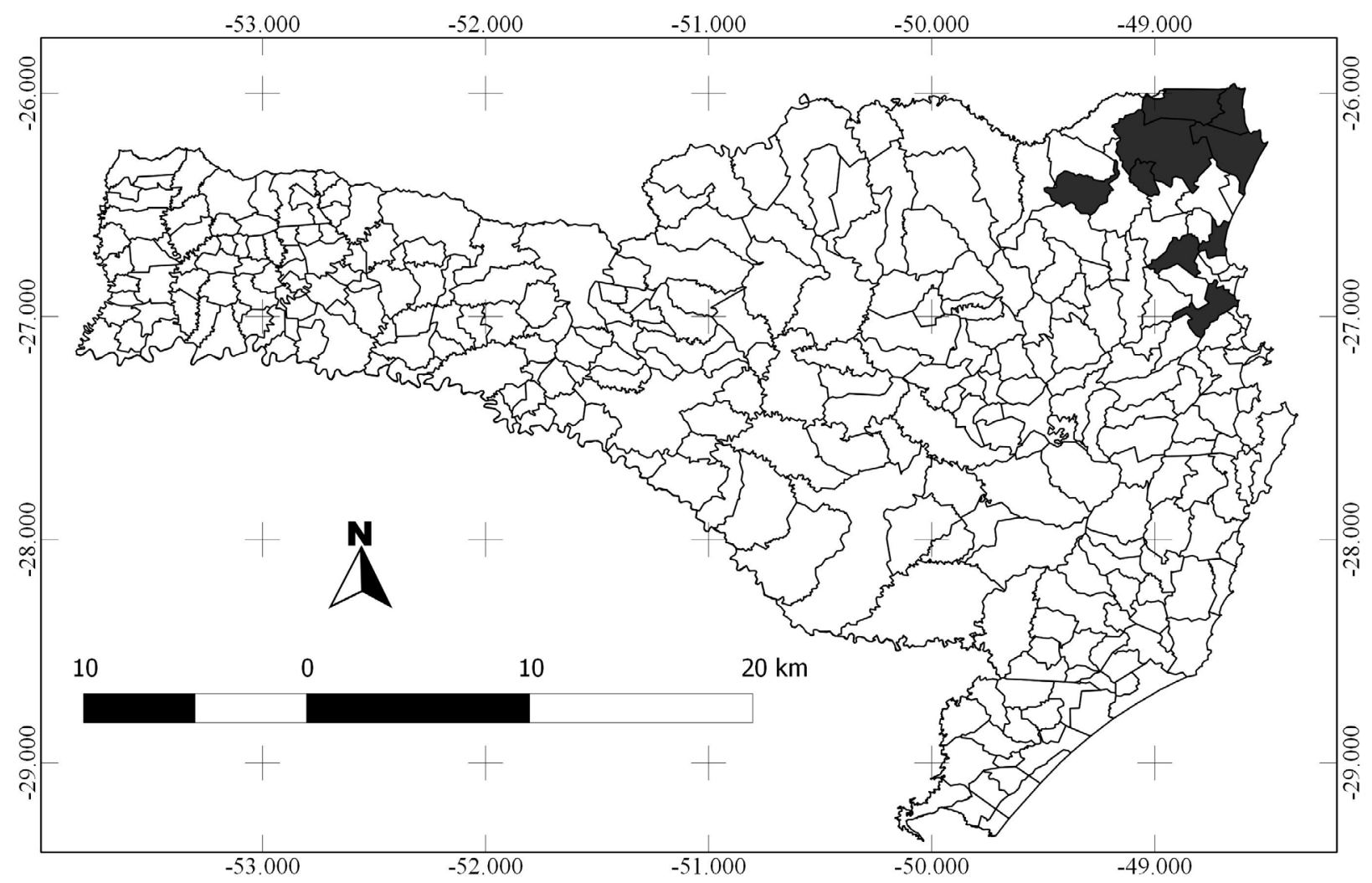

Fig. 10. Mapa de distribuição da espécie Geonoma elegans Mart. em Santa Catarina.

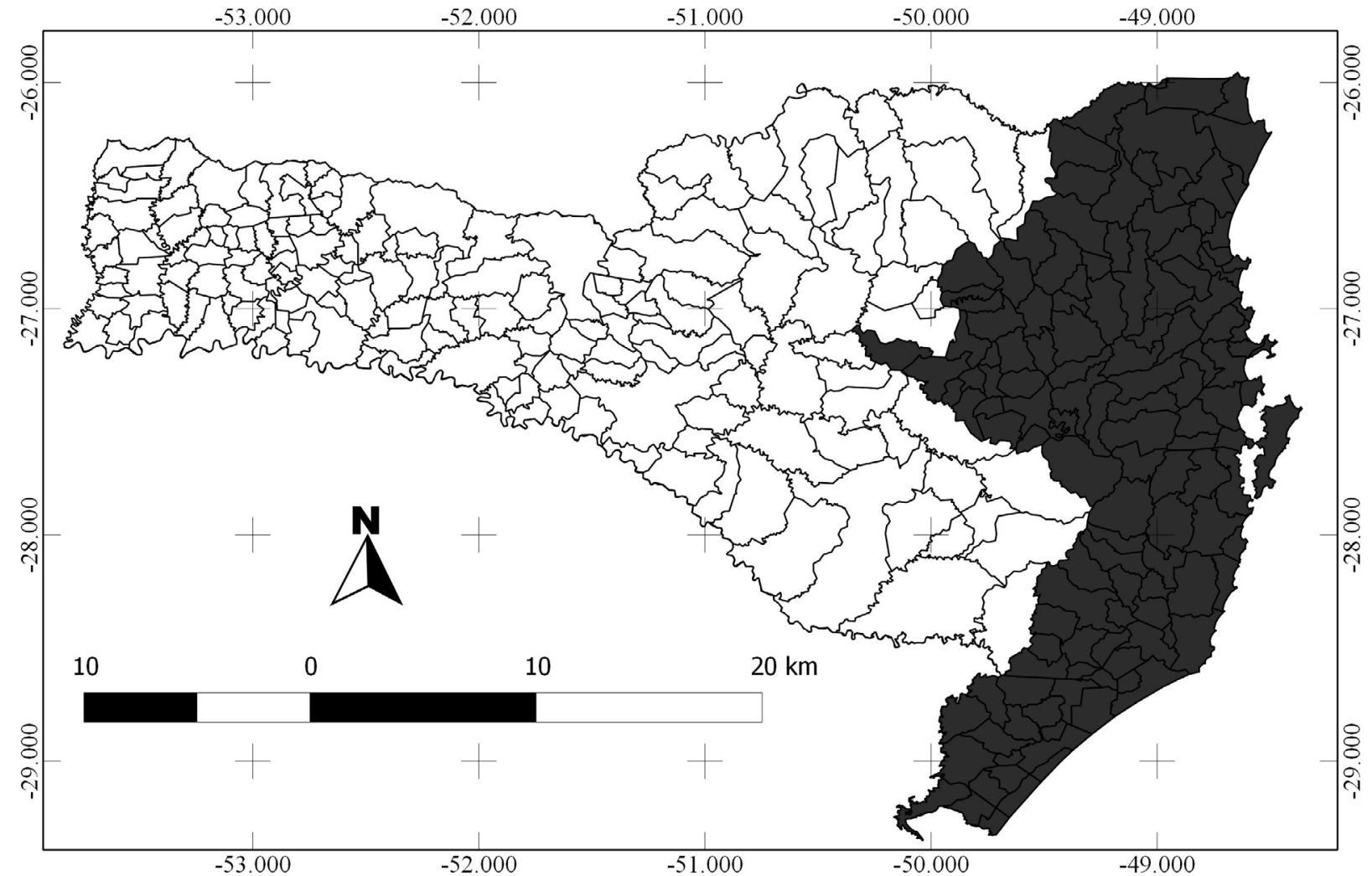

Fig. 11. Mapa de distribuição da espécie Geonoma gamiova Barb.Rodr. em Santa Catarina. 


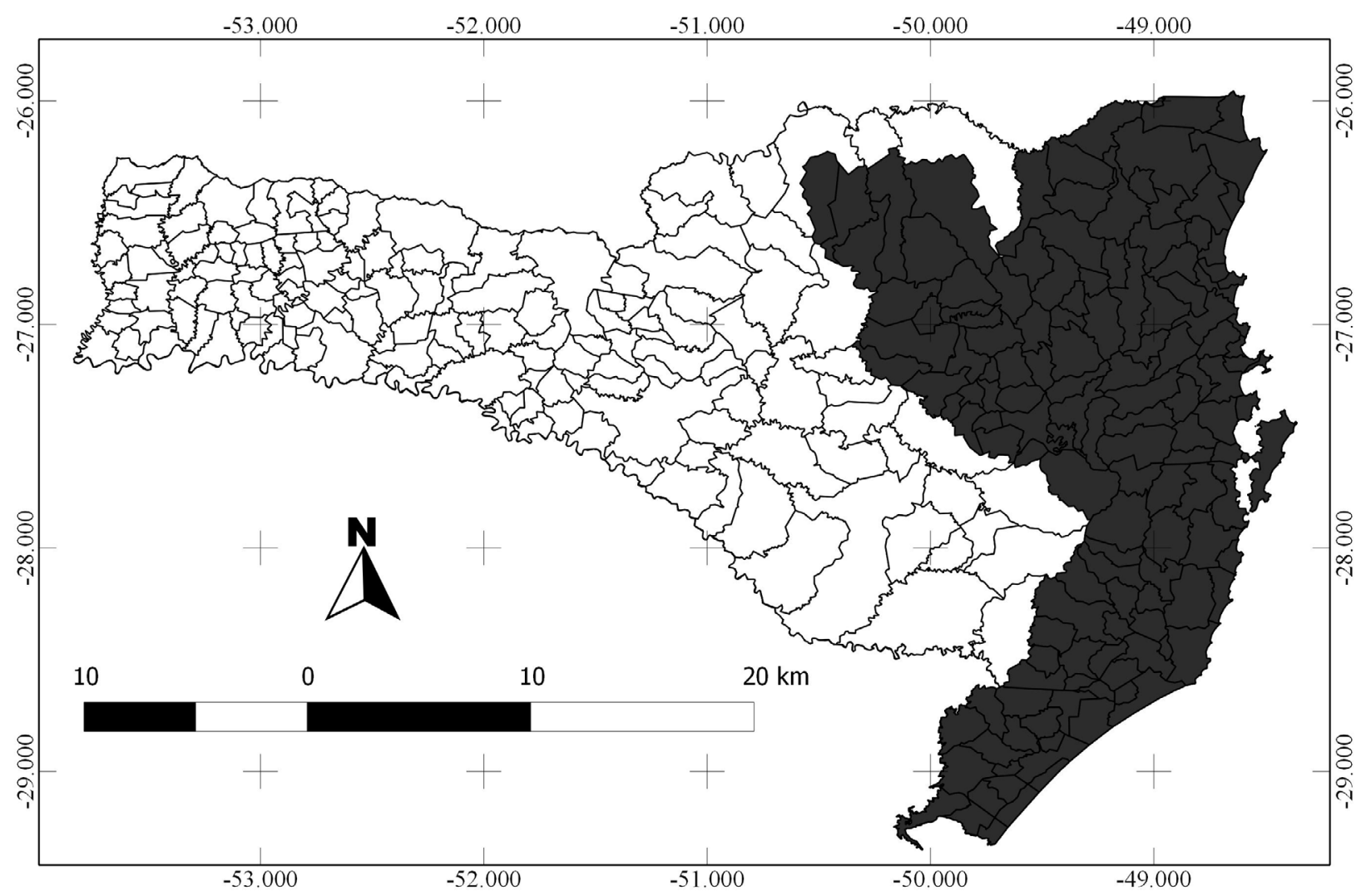

Fig. 12. Mapa de distribuição da espécie Geonoma schottiana Mart. em Santa Catarina.

Nomes populares: aricanga-do-brejo, aricanga-do-capão, aricanga-de-folha-miúda, ouricana.

Material examinado: BRASIL, SANTA CATARINA, Araquari, Ilha dos Papagaios, 14.IV.2005, W. S. Mancinelli 221 (JOI); Criciúma, Primeira Linha, 12.IX.1997, R. Santos et al. 304 (CRI); Florianópolis, Pântano do Sul, 20.I.1971, A. Bresolin 108 (HBR); Forquilhinha, Parque Ecológico, 15.VII.1992, J. Zocche $s / n^{\circ}$ (CRI 1285), São Pedro, 7.IX.1995, C. M. Martinello \& Z. P. Topanotti $s / n^{\circ}$ (CRI 4879); Itajaí, Morro da Fazenda, 4.III.1954, R. Reitz \& R. M. Klein 1715 (HBR); Itapoá, Reserva Volta Velha, 19.XII.2015, G. A. Elias et al. 4 (CRI); Joinville, Estrada Dona Francisca, 21.VI.1957, R Reitz \& R. M. Klein 4402 (HBR); Porto Belo, 30.VI.2010, J. L. Schmitt et al. 2950 (FURB); São Francisco do Sul, Vila da Glória, 12.XII.2005, J. Z. Berger 231 (JOI); Schroeder, Rancho Bom, 19.II.2010, S. Dreveck 1821 (FURB); Santo Amaro da Imperatriz, Pilões, 3.V.1956, R. Reitz \& R. M. Klein 3208 (HBR).

Material adicional examinado: BRASIL, RIO GRANDE DO SUL, Pelotas, Praia do Laranjal, localidade de Barro Duro, 31.VII.2012, K. Soares 36 (HDCF).

Espécie esciófita e seletiva xerófita com ampla distribuição na Floresta Atlântica (ES, RJ, SP, PR, SC, RS e MG) (Leitman et al. 2015) nas florestas de encosta, restingas e capoeirões, bem como em florestas ciliares da região Sudeste, até $1.600 \mathrm{~m}$ de altitude (Reitz 1974, Lorenzi et al. 2010, Soares et al. 2014). Em Santa Catarina ocorre com uniformidade, sendo mais comum na região sul do Estado, ocorrendo desde 10 até $700 \mathrm{~m}$ de altitude. $\mathrm{Na}$ região norte aparece com 2 a 4 exemplares por $100 \mathrm{~m}^{2}$, sendo considerada rara (Reitz 1974).

Suas folhas são utilizadas na cobertura de casas rústicas, e quando desidratadas, para decoração, tendo mercado de exportação. Além disso, os pecíolos podem servir de matéria prima para cordoaria e artesanato fibroso (Reitz 1974, Lorenzi et al. 2010).

7 Syagrus Mart., Hist. Nat. Palm. II. 129. t. 89. 1824. Tipo: S. cocoides Mart. Hist. Nat. Palm. 2: 130. 1826.

O gênero pertence à subfamília Cocosoideae, tribo Cocoeae, subtribo Butiinae (Reitz 1974). Apresenta ampla distribuição, no entanto quase totalmente restrito a América do Sul, sendo representado por 57 espécies, 51 ocorrendo no Brasil (Lorenzi et al. 2010, Soares et al. 2013, Noblick et al. 2014, Leitman et al. 2015, Noblick \& Meerow 2015). Em Santa Catarina, o gênero está representado por uma única espécie, Syagrus romanzoffiana (Cham.) Glassman.

7.1 Syagrus romanzoffiana (Cham.) Glassman, Fieldiana, Bot. 31: 382, 1968.

Tipo: BRASIL. SANTA CATARINA, s.d., L.K.A. Von Chamarisso s.n. (Holótipo, LE, destruído; lectótipo, Chamisso, 1822, t. 5-6, n.v.).

(Figs. 14A-E, 13) 
Estipe solitário, 2-26 m alt., 20-55 cm diâm. Folhas pinadas, 6-37 contemporâneas; pseudopecíolo com margens fibrosas, 1,1-2,4 m compr.; pecíolo até $13 \mathrm{~cm}$ compr.; raque 1,4-5,3 m compr. (inicialmente acanalada adaxialmente, tornando-se aguda na extremidade), 130-270 pinas de cada lado; pinas dispostas irregularmente ao longo da raque em grupos de 2-9, inseridas em vários ângulos, conferindo à folha um aspecto plumoso, as da parte mediana da raque 53-111 × 1,3-4,8 cm. Inflorescência interfoliar, até $1,9 \mathrm{~m}$ compr.; pedúnculo $58-82 \mathrm{~cm}$ compr.; profilo $30-60 \mathrm{~cm}$ compr.; bráctea peduncular profundamente sulcada longitudinalmente, $100-223 \mathrm{~cm}$ compr. total, parte expandida 82-189 × 12-38 cm; raque da inflorescência 21$119 \mathrm{~cm}$ compr., $37-352$ ráquilas, $12-83 \mathrm{~cm}$ compr. Flores amarelas ou cremes; estaminadas $10 \mathrm{~mm}$ compr.; pistiladas 5-8 mm compr. na mesma inflorescência. Fruto amarelo ou alaranjado, ovoide, alongados ou quase redondos, 1,9-4,2 × 1,3-2,9 cm; mesocarpo amarelo, mucilaginoso; endocarpo 1,2-2,8 × 1,1-2,6 cm; endosperma irregular (giboso). Eófilo simples.

Nomes populares: jerivá, gerivá, coqueiro-jerivá, jeribá, coqueiro, coco-de-catarro, coco-babão, baba-de-boi, cocode-cachorro.

Material examinado: BRASIL, SANTA CATARINA, Blumenau, Nova Rússia, 18.XII.2003, F. Bosio $s / n^{\circ}$ (FURB 1772); Brusque, Azambuja, 20.IX.1947, R. Reitz 1878 (HBR); Capinzal, 21.XII.1962, R. Reitz \& R. M.
Klein 14368 (HBR); Chapecó, 31.XII.1963, R. Reitz \& R. M. Klein 16655 (HBR); Itapoá, Reserva Volta Velha, 19.XII.2016, G. A. Elias et al. 2 (CRI); Orleans, Parque Estadual da Serra Furada, 11.IV.2015, G. A. Elias 9 (CRI); São Ludgero, Itapiranga, 1.I.1964, R. Reitz \& R. M. Klein 16811 (HBR); Itapoá, Reserva Volta Velha, 11.IV.2015, G. A. Elias 2 (CRI); Treviso, Cirenaica, 27.I.2010, M. Verdi, D. H. Klettenberg \& G. Klemz 4019 (FURB); Turvo, 30.I.2008, J. G. Cemin $s / n^{\circ}$ (CRI 7890).

Material adicional examinado: BRASIL, RIO GRANDE DO SUL, Canguçu, Localidade Florida, 30.VIII.2012, $K$. Soares 35 (HDCF 6273).

Espécie heliófita e seletiva higrófita, ocorre no Uruguai, Argentina, Paraguai e Brasil (sudeste da BA, GO, DF, MG, MS, SP, RJ, ES, PR, SC e RS) (Soares et al. 2014) é abundante nos agrupamentos vegetais primários, sendo comum em solos úmidos, brejosos ou que ficam temporariamente encharcados. Em Santa Catarina está distribuída de forma irregular, praticamente, por todas as formações vegetais, entre 10 e 800 m de altitude (Reitz 1974).

Syagrus romanzoffiana é uma das espécies com maior Valor Potencial de Exploração Sustentável da região Sul de Santa Catarina (Elias \& Santos 2016), apresenta vasta utilização, sendo a palmeira mais utilizada para paisagismo no sul do Brasil, além de frutos atrativos para fauna com propriedades bioquímicas e nutricionais. (Zimmermann et al. 2011, Soares et al. 2014, Elias et al. 2015).

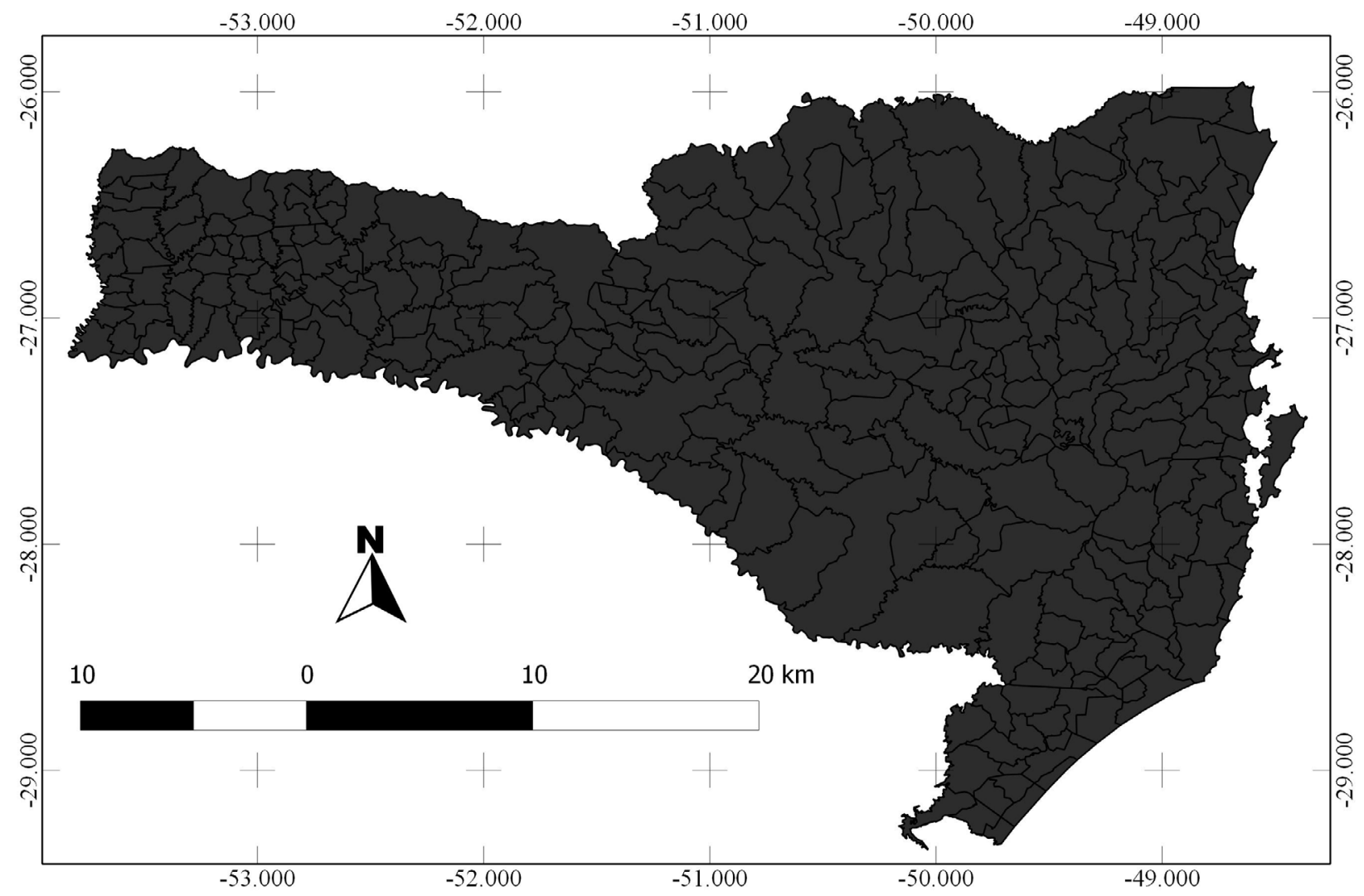

Fig. 13. Mapa de distribuição da espécie Syagrus romanzoffiana (Cham.) Glassman em Santa Catarina. 


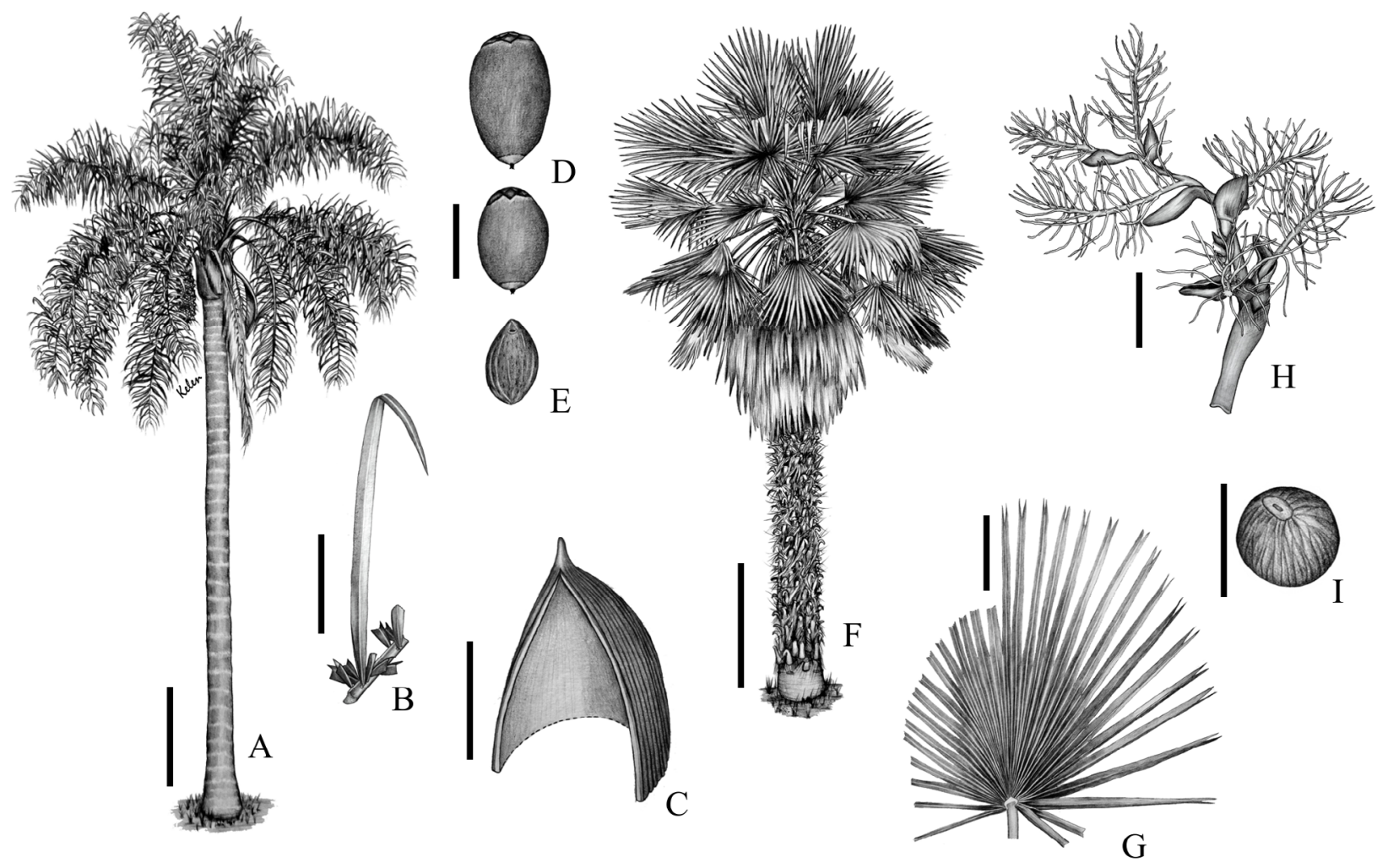

Figs. 14A-I. A-E. Syagrus romanzoffiana (K. Soares 35). A. hábito; B. detalhe da folha mostrando inserção das pinas; C. detalhe da bráctea peduncular mostrando a superfície externa sulcada; D. frutos; E. endocarpo. F-I. Trithrinax acanthocoma ( $K$. Soares 31 ). F. hábito; G. folha. H. inflorescência; I. endocarpo. Barras: Figs. A, F =1 m; Figs. B, G, $\mathbf{H}=20 \mathrm{~cm}$; Fig. $\mathbf{C}=10 \mathrm{~cm}$; Figs. D, E, $\mathbf{I}=2 \mathrm{~cm}$.

8 Trithrinax Mart., Hist. Nat. Palm. 2: 149. 1837. Tipo: T. brasiliensis Mart., Hist. Nat. Palm. 2: 150. 1837.

O gênero pertence a subfamília Coryphoideae, tribo Corypheae (Reitz 1974, Dransfield et al. 2008), considerado pequeno por apresentar apenas cinco espécies, sendo três ocorrentes no Brasil e uma endêmica (Pingitore 1978, Soares et al. 2014, Leitman et al. 2015).

8.1 Trithrinax acanthocoma Drude, Gartenflora 27: 361. 1878.

Tipo: BRASIL. RIO GRANDE DO SUL, s.d., A.F.M. Glaziou 9014 (holótipo, C!).

(Figs. 14F-I, 15)

Palmeira monoica; estipe solitário, 2,4-13 m alt., 19-40 cm diâm., recoberto pelas bainhas das folhas já caídas e por uma rede de fibras muito rígidas, dispostas oblíquas e entrecruzadas, engrossadas na parte superior e terminadas em agulhões lignosos, longo persistentes, rígidos, 11-29 cm compr. Folhas palmado-flabeliformes, 15-58 contemporâneas, verde escuras na parte de cima e cobertas por indumento esbranquiçado na parte de baixo; bainha com 19-29 cm compr., com um reforço central; pecíolo 67-93 × 3-6 cm, rígido, pouco flexível, exceto pela curvatura próxima da bainha, margem lisa $\mathrm{e}$ afiada, espessura constante, terminado em uma hástula córnea triangular; 31-49 segmentos (pinas), 72-112 $\times$ 5-6 cm, plissados e partindo de um ponto comum, os maiores na parte central, diminuindo de tamanho e largura conforme sua disposição segue lateralmente, todos os segmentos são unidos, separando-se então pela metade do seu comprimento (42-51 cm finais) e terminados em uma ponta dupla pungente, fendida até 1/5 do comprimento total (4-19 $\mathrm{cm}$ a partir da ponta). Inflorescência interfoliar ramificada ao nível de terceira ordem, flores amarelo-creme, estaminadas $12 \mathrm{~mm}$ compr.; pistiladas 6-10 mm compr. na mesma inflorescência. 6-8 ramificações principais de $22-52 \mathrm{~cm}$ compr.; pedúnculo recurvado em "S", 45-91 × 2,5-4,2 cm; 6-9 brácteas pedunculares (uma para cada ramificação), 11-22 × 3-15 $\mathrm{cm}$, parte expandida com 13-17 cm de compr.; profilo com $30-37 \times 6-8 \mathrm{~cm} ; 34-50$ ráquilas por segmento, $5-15 \mathrm{~cm}$ de compr. Frutos globosos, amarelo-esbranquiçados quando maduros, 1,7-4,0 cm diâm.; mesocarpo carnoso que se destaca facilmente do endocarpo, uma única semente. Eófilo simples.

Nomes populares: buriti, buriti-palito, carandaí.

Material examinado: BRASIL, SANTA CATARINA, Araranguá, Morro dos Conventos, 10.I.1957, L. B. Smith \& R. Reitz 9940 (HBR); Morro dos Conventos, 16.VII.1959, R. Reitz \& R. M. Klein 8942 (HBR), 20.II.2016, G. A. Elias 17 (CRI); Bom Retiro, 10.I.1948, R. Reitz 1993 (HBR). 


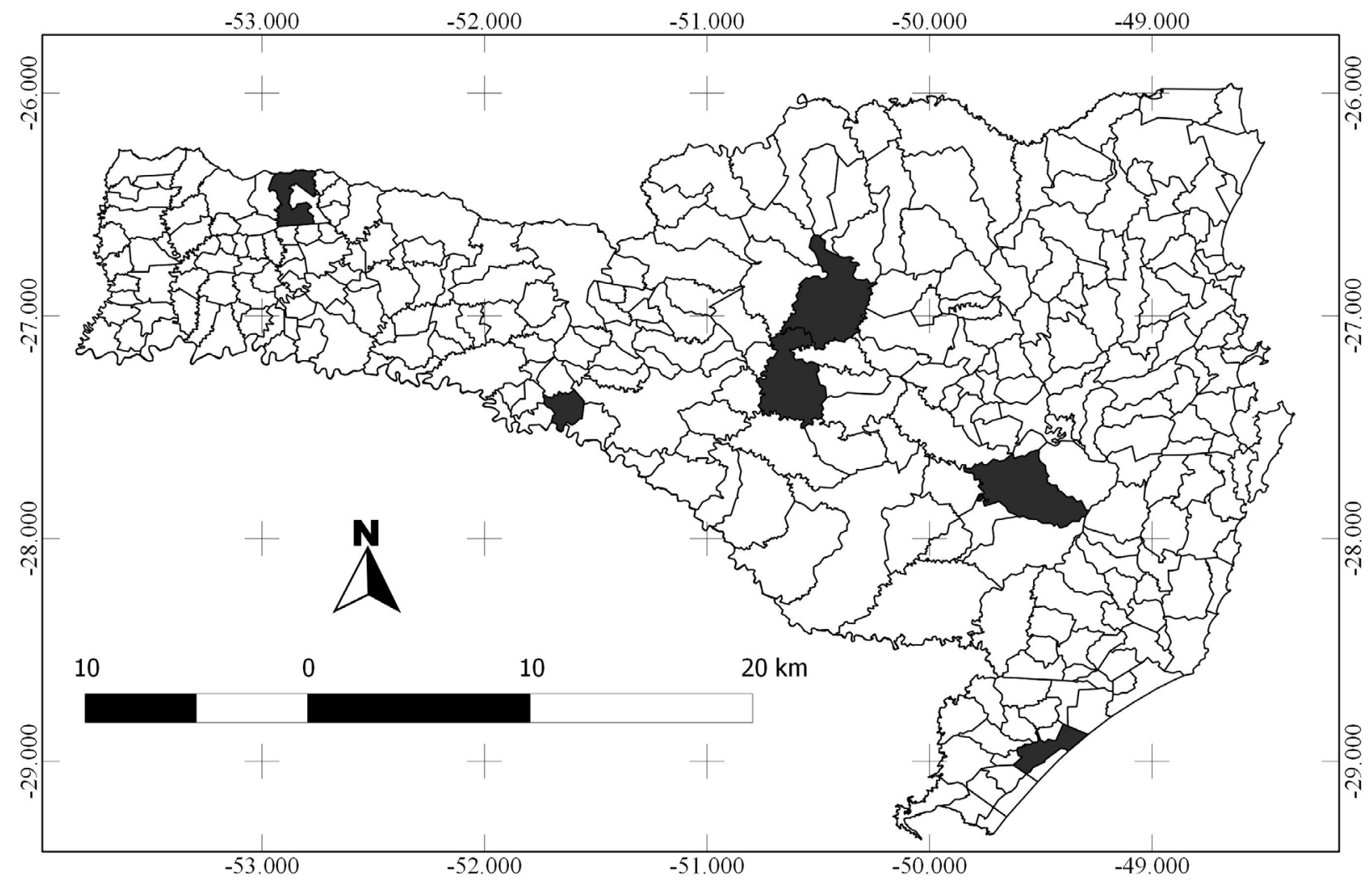

Fig. 15. Mapa de distribuição da espécie Trithrinax acanthocoma Drude em Santa Catarina.

Material adicional examinado: BRASIL, RIO GRANDE DO SUL, Nova Prata, cultivada, 26.VIII.2012, K. Soares 31 (HDCF 6269).

Espécie seletiva heliófita e higrófita que ocorre nos três estados do Sul (PR, SC e RS), e foi erroneamente descrita em outros trabalhos científicos e coleções botânicas como sendo T. brasiliensis (Reitz 1974, Sühs \& Putzke 2010, Carvalho 2010, Soares et al. 2014). Uma vez que $T$. brasiliensis é uma espécie muito rara e que ocorre apenas no centro e sul do RS, em altitudes inferiores a $450 \mathrm{~m}$, associada às rochas, em relevos inclinados e com grande exposição solar, onde forma populações pequenas e possui menor porte, folhas verde oliva ou grizáceas com segmentos bifurcados até metade do seu comprimento total, espinhos das bainhas menores e decíduos após a queda da folha, permanecendo somente as bainhas (Soares et al. 2014).

A mais recente revisão para o gênero Trithrinax (Cano et al. 2013) sugere o reconhecimento de apenas uma espécie com duas variedades: $T$. brasiliensis var brasiliensis e $T$. brasiliensis var. acanthocoma. Embora estes autores tenham reconhecido diversas características morfológicas distintas entre os táxons, as análises moleculares não encontraram relevantes diferenças, e os resultados não foram esclarecidos, possivelmente a análise não foi satisfatória. No entanto, devido as grandes variações morfológicas entre os táxons, diferente tipo de vegetação em que eles ocorrem (habitat) e crescimento diferenciado, preferimos aqui reconhecê-los como espécies distintas, seguindo Pingitore (1978), Lorenzi et al. (2010) e Soares et al. (2014).

Em Santa Catarina, T. acanthocoma pode ser observada em distribuição irregular e de forma esporádica no Planalto Catarinense em pequenos agrupamentos, entre 950 e $1.200 \mathrm{~m}$ de altitude, é característica da Floresta Ombrófila Mista, porém, apresenta elemento estranho, no Morro dos Conventos, em Araranguá e no Parque Estadual de Itapeva, em Torres, RS, nos domínios da Floresta Ombrófila Densa (Soares et al. 2014). Este curioso fato foi atribuído por Reitz (1974), aos viajantes que se utilizavam dessa rota para o planalto, tendo estas localidades, na "Zona da mata pluvial da encosta atlântica", como possível parador das caravanas.

Possui larga utilização na ornamentação de jardins. Suas folhas, em estado natural, podem ser utilizadas como leque ou vassouras, quando secas, fornecem fibra que é utilizada na manufatura de chapéus e utensílios fibrosos (Reitz 1974).

\section{AGRADECIMENTOS}

À Coordenação de Aperfeiçoamento de Pessoal de Nível Superior (CAPES) pela bolsa de Doutorado concedida ao primeiro autor. Aos Curadores dos Herbários visitados pela permissão para consulta aos acervos. À Profa. Dra. Vanilde Citadini-Zanette e ao Prof. Dr. Ademir Reis pelas valiosas contribuições. À Universidade do Extremo Sul Catarinense (UNESC) pelo apoio e infraestrutura fornecida para o desenvolvimento do trabalho. 


\section{REFERÊNCIAS}

Balick, M.J. \& Beck, H.T. 1990. Useful Palms of the World: A Synoptic Bibliography. Columbia University Press, New York. 724 p.

Barbosa Rodrigues, J. 1907. Supplementum ad Sertum Palamarum Brasilensium. Contributions du Jardin Botanique de Rio de Janeiro 6:1-13.

Cano, Á., Perret, M. \& Stauffer, F.W.A. 2013. A revision of the genus Trithrinax Cryosophileae, Coryphoideae, Arecaceae). Phytotaxa 136(1):1-53.

Carvalho, P.H.R. 2010. Espécies arbóreas brasileiras. Embrapa Informações Tecnológicas, Brasília, vol. 4, p. 644.

Cascante, A. 2000. Additions to the genus Bactris (Arecaceae) of Mesoamerica. Palms 44(3):146-150.

Centro Nacional de Conservação da Flora - CNCFlora. 2012. Disponível em: https://goo.gl/Hd6YqZ. Acessado em 23.04.2015.

Coradin, L., Siminski, A. \& Reis, A. 2011. Espécies Nativas da Flora Brasileira de Valor Econômico Atual ou Potencial: Plantas para o Futuro - Região Sul. Ministério do meio Ambiente, Brasília. 934p.

Dransfield, J., Uhl, N.W., Asmussen, C.B., Baker, W.J., Harley, M.M. \& Lewis, C.E. 2008. Genera Palmarum: the evolution and classification of palms. Kew Publishing Royal Botanical Garden, Londres. 732p.

Elias, G.A., Corrêa, P.F., Citadini-Zanette, V. \& Santos, R. 2015. Arecaceae: análise bibliométrica das espécies nativas do estado de Santa Catarina, Brasil. Ciência e Natura (37)1:85-92.

Elias, G.A. \& Santos, R. 2016. Produtos Florestais Não Madeireiros e Valor Potencial de Exploração Sustentável da Floresta Atlântica no sul de Santa Catarina. Ciência Florestal 26(1):235-248.

Galetti, M. \& Aleixo, A. 1998. Effects of palm heart harvesting on avian frugivores in the Atlantic forest of Brazil. Journal of Applied Ecology 35:286-293.

Glassman, S.F. 1999. A Taxonomic Treatment of the Palm Subtribe Attaleinae (Tribe Cocoseae). Illinois Biological Monographs 59:1414.

Henderson, A. 2002. Evolution and Ecology of Palms. The New York Botanical Garden Press, New York. 259p.

2011. A revision of Geonoma (Arecaceae). Phytotaxa 17:1-271.

Henderson, A., Galeano, G.\& Bernal, R. 1995. Field Guide to the Palms of the Americas. Princeton University Press, Princeton, New Jersey. $352 \mathrm{p}$.

Hoffmann, J.F., Barbieri, R.L., Rombaldi, C.V. \& Chaves, F.C. 2014. Butia spp. (Arecaceae): An overview. Scientia Horticulturae 179:122-131.

Instituto Brasileiro de Geografia e Estatística - IBGE. 2012. Manual técnico da vegetação brasileira. Rio de Janeiro. 274 p.

International Plant Names Index - IPNI. 2016. Disponível em: http:// www.inpi.org. Acessado em 06.10.2016.

Kahn, F. 2008. The genus Astrocaryum (Arecaceae). Revista Peruana de Biología 15(1):31-48.

Leitman, P., Soares, K., Henderson, A., Noblick, L. \& Martins, R.C. 2015. Arecaceae in Lista de Espécies da Flora do Brasil. Jardim Botânico do Rio de Janeiro. Disponível em: http://reflora.jbrj.gov.br/jabot/ floradobrasil/FB15670. Acessado em 22.04.2015.
Lorenzi, H., Noblick, L.R., Kahn, F. \& Ferreira, E. 2010. Flora Brasileira: Arecaceae (Palmeiras). Instituto Plantarum, Nova Odessa, São Paulo. $432 \mathrm{p}$.

Maunder, M., Lyte, B., Dransfield, J. \& Baker, W. 2001. The conservation value of botanic garden palm collections. Biological Conservation 98:259-271.

McNeill, J., Barrie, F.R., Buck, W.R., Demoulin, V., Gruter, W., Hawksoworth, D.L., Herendeen, P.S., Knapp, S., Marhold, K., Prado, J., Prud'Homme Van Reine, W.F., Sith, G.F., Wiersema, J.H. \& Turland, N.J. 2012. International Association for Plant Taxonomy: Article 8. Disponível em: http://www.iapt-taxon.org/nomen/ main. php. Acessado em 04.05.2015.

Müller, C.V. 2011. Geonoma gamiova. In Espécies nativas da Flora Brasileira de Valor Econômico Atual ou Potencial: Plantas para o Futuro - Região Sul (L. Coradin, A. Siminski \& A. Reis, eds.). Ministério do Meio Ambiente, Brasília, p. 262-265.

Nazareno, A.G. \& Reis, M.S. 2014. At risk of population decline? An ecological and genetic approach to the threatened palm species Butia eriospatha (Arecaceae) of Southern Brazil. Journal of Heredity 105(1):120-129.

Noblick, L.R. 1998. Butia eriospatha. The IUCN Red List Threatened Species. Disponível em: www.iucnredlist.org/details/38462/0. Acessado em: 08.05.2015.

Noblick, L.R. Lorenzi, H. \& Souza, V.C. 2014. Four new taxa of acaulescent Syagrus (Arecaceae) from Brazil. Phytotaxa 188(1):1-13.

Noblick, L.R. \& Meerow, A.W. 2015. The transfer of the Genus Lytocaryum to Syagrus. Palms 59(2):57-62.

Pingitore, E.J. 1978. Revision de las species del genero Trithrinax (Principales). Revista Del Instituto Municipal de Botânica 4:95-109.

Pires, A.S. 2006. Perda de diversidade de palmeiras em fragmentos de Mata Atlântica: Padrões e Processos. Tese 119f., Universidade Estadual Paulista Júlio de Mesquita Filho, São Paulo.

Reitz, R. 1974. Palmeiras. In Flora Ilustrada Catarinense. Herbário Barbosa Rodrigues, Itajaí. 189p.

Soares, K.P., Longhi, S.J., Neto, L.W. \& Assis, L.C. 2014. Palmeiras (Arecaceae) no Rio Grande do Sul, Brasil. Rodriguésia 65(1):113-139.

Soares, K. \& Witeck, L. 2009. Ocorrência de Butia capitata e outras espécies do gênero Butia na região central do Rio Grande do Sul, Brasil. In Butia: Ecossistema Único em el Mundo (G. Geymonat \& N. Rocha, eds.). Casa Ambiental de Castillos, Castillos, p. 37-41.

Sühs, R.B. \& Putzke, J. 2010. Nota sobre a ocorrência de uma população de Trithrinax brasiliensis Martius (Arecaceae) no Vale do Rio Pardo, Rio Grande do Sul, Brasil. Pesquisas Botânica 61:330-332.

Tomlinson, P. 1990. The Structural Biology of Palms. Clarendon Press, Oxford. 477 p.

Vibrans, A.C., Sevegnani, L., Lingner, D.V., Gasper, A.L. \& Sabbagh, S. 2010 Inventário Florístico Florestal de Santa Catarina (IFFSC): aspectos metodológicos e operacionais. Pesquisa Florestal Brasileira 30(64):291-302.

Zimmermann, T.G., Begnini, R.M. \& Silva, F.R. 2011. Syagrus romanzoffiana. In Espécies nativas da Flora Brasileira de Valor Econômico Atual ou Potencial: Plantas para o Futuro - Região Sul (L. Coradin, A. Siminski \& A. Reis, eds.). Ministério do Meio Ambiente, Brasília, p. 812-819. 